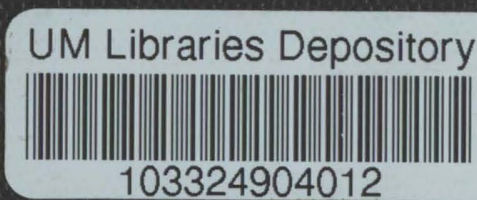



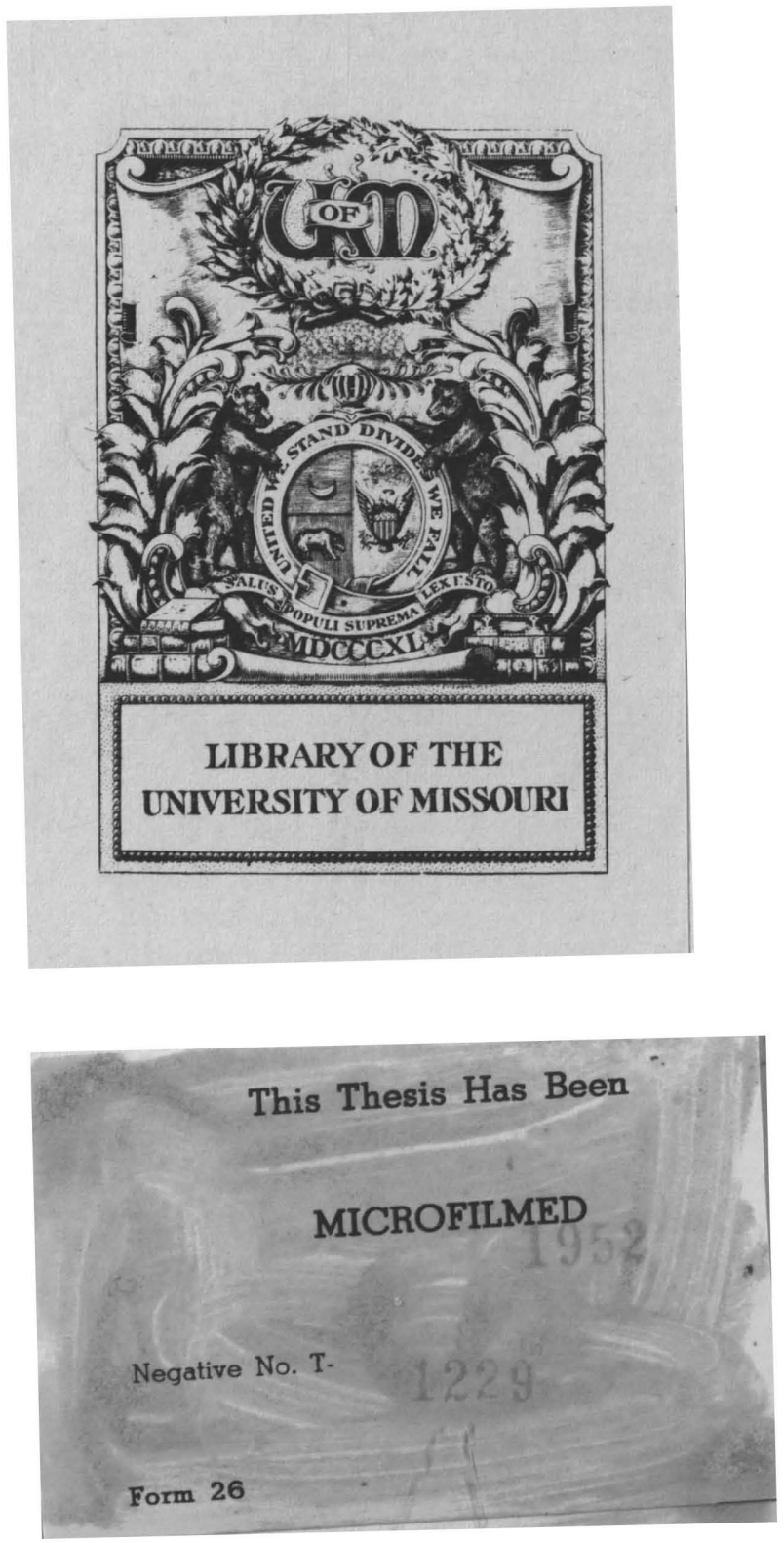




A COMPARISON OP SOMT

STANDARDS OF RADIOACTIVITY.

by

MORTIS RANDALL, A. B. I \&
III
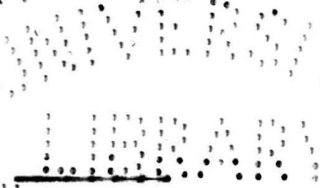

SUBMITTED IN PARTIAL FULFILLMFNT OF THE

REQUTREMANTS FOR THE DFGRHE OF

MASTFR OF ARTS.

in the

GRADUATTE DEPARTMMENT

(COLLFGE OF ARTS AND SCTHANCE)

of the

UNIVIRRSITY OF MISSOURI

2909.

RECEIVED

JUN 1.1909

JNIV. OF MO. 

CONTHANTS.

Introduetion. 7

Oranium standards 7

Radium standards 11

Air Standard 12

Fall of Potential standard 13

C.G.S. Flectrostatie Standard 14

Relations between Standards. 15

General Methods 18

Fxperimental Methods aud Results 18

Source of Radium thanation 18

Determination of Uranium in Uraninite 19

Method of Analysis 19

Results of Analysis 25

Loss at One Hundred Degrees 25

The Standard Stock Solutions of Uraninite 26

Storing of the Standard Samples 30

Form of Flasks $\quad 30$

The Samples. 34

Apparatus for Separating the Radium Fmanation 36

Strutt Apparatus 37

Sehlundt and Moore Apparatus 43

Schlundt and Moore Apparatus for Water $\quad 47$ 

(3)

Drying Train 50

Boltwood Apparatus 53

MeCoy Apparatus $\quad 57$

Apparatus for Radium fmanation in Minerals 60

Flectroscopes $\quad 63$

Boltwood Form. Number $2 \quad 63$

Picein used for Hounting Glass Plates 64

Schlundt Form (New) Nurber 4

Schmidt Forn Number 5

Schlundt Form Number 8

Determination of Capacity of Hlectroscopes 78

Harms Air Condenser 78

Source of Potential $\quad 80$

Voltmeter $\quad 82$

Determination of E.M.F. of battery and

Calibration of Scale of Licroscope 84

Form of Calibration Curve $\quad 89$

Joint Capacity of Condenser and Electroscope 97

Capacity of Electroscope, Ifethod 99

Results of Capacity Me asurmants 102

"Crawl Effect" 102

Bearins on Anomalous Results of Seplundt .

$\begin{array}{ll}\text { and noore } & 107\end{array}$ 



\title{
(4)
}

\author{
Annaalous Air Leak \\ 107 \\ Determination of Relation between Boltwood Fmanatinn \\ Standard and C. G. S. Flectroststic 109 \\ Method 109 \\ Results 118. \\ Diseussion 121 \\ Suramary of Results $\quad 125$
}

\section{Iist of Illustrations.}

Fig. 1. Storage Flasks 32

Fig. 2. The Strutt Apparatus 39

Fis. 3. Sehlundt and Moore Apparatus 44

Fig. 4. Schlundt and Moore Apparatus for

$\begin{array}{ll}\text { Water Samples } & 48\end{array}$

Fig. 5. Drying Train 51

Fig. 6. Beltwood Apparatus. 55

Fig. 7. MeCoy Apparatus 58

Fi: 8. Apparatus for Separating the Radium Fmanation Decluded in Minerals 61

Fig. 9. Electroscope Number 2

FIg. 10. Hlectroseope Number 8 

(5)

Fig. 1l. Detail of Leaf Systems 66

Fig. 12. Cradle for Reading Iicroscope 72

Fig. 13. Electroseope Number 5

Fig. 14 Electroseope Number 4

F1g. 15 Harms Air Condenser 79

Fig. 16. Parts of Harms Condenser - 79

Fig. 17. Storame Batteries 81

F1g. 18 Dry Batteries 81

\section{List of Curres.}

No. 1. Calibration Curve Flectroseope No. 29

No. 2. Calibration Curre Flectroseope No. 4a 91

No. 3. Calibration Curve Flectroscope No. 4b 92

No. 4. Calibration Curve Flectroscope No. 4e 93

No. 5. Calibration Curve Flectroscope No. 599

No: 6. Calibration Curve Flectroscope No. 595

No. 7. Calibration Curve Electroscope Na. 896

No. 8. Example of Anomalous Air Leak 110

No. 9. Example of Anomalous Air Leak 111

No. 10, Influence of the Concentration of

the Radium Jimanation upon the

Ionization per gran Uranium

Flectroscope No. 8 

(6)

No. 11. Influence of the Concentration of

the Radium Fmanation of the Ion-

ization Current per gram of Uran-

Ium Flectroseope No. 4

121 



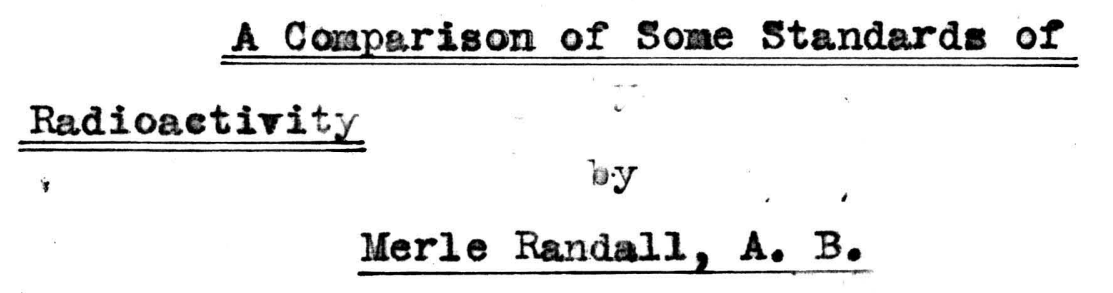

\section{Introduction.}

Frer since Beequerel made his study of the photographic action of uraniua salts (1) various compounds of this elenent have been used as a standard, to which the radioactivity of the several $\wedge^{2 e t}$ ive elements could be referred. At first the methods of measurment were rather crude and a rough standard was suffieient to meet the needs of investigators.

$$
\text { As late as } 1904 \text { we find Strutt (2) in }
$$

his study of the radioativity of ordinary mater1als using as a standard the activity of a "erystal of uranyl nitrate four by twelve milli-

(1) Becquerel, H. Conptes rendus, 122, pp. $420,501,599,689,762,1086,1896$.

(2) Strutt, R. J., Phil. Mleg., 5, 680, 1903; Nature, 67, 369, 1903. 



\section{(8)}

meters"." Allan (1) studied the aetivity of freshly fallen snow and took as his standard the actirity of a given vreight of uraniura, in uranium oxide. Flster and Geitel (2) studied the radioaetivity of elay and spring sediments They took for conaparison the activity of uranyl potassium sulphate., Blane (3) used as a standard an equal weight of uranium nitrate.

MeCoy (4) has proposed to use as a stand-

(1) Allan, S. J., Physie. Rev., 16, pp. $237,306,1903$.

(2) Blster and Geitel, Physik. 2.5 , 321, 1904.

(3) Blane, G. A., Phil. Mase, 9, 148, 1905.

(4) MeCoy, H. N., Ber. d. Chem. Geseil,, 37, 2641, 1904; Physic. Rer., 20, 381, 1905; J. Am. Chem. Soc., 27, 391, 1905; Phil. Hag., 9, $176,1906$.

Goettseh, H. M., Thesis, University of Chicago. The Absorption Coefficients of Uranium Compounds .

MeCoy and Ross, J. Am. Chem. Soe., 29, $1698,1907$. 



\section{(9)}

art of activity the lonization produced between parallel plates by the alpha rays from one square eentimeter of urano-uranic oxide (1) of sufficlent thickness to give the maximum alpha ray activity. MeCoy has shown (2) that this standard is reprodugable with a high degree of aceuracy. Boltwood (3) has used the ionization of thin films of urano-uranie oxide which had a negligfble arnount of alphe rays absorbed by the film itself as a standard.

The ratio of radium to uranium in an old natural mineral is a constant (4). Boltwood has

(1) MeCoy and Ashran, Am, Jour. Sei., 26, $528,1908$.

(2) MeCoy, loc, eit.

(3) Boltwood, B. B., Am. Jour. Sei., 25, 409,1908 .

(4) Boltwood, B. B., Am. Jour. Sei., 18, 97, 1904; Nature, 70, 80, 1904; Phil. Mag., 9, $599,1905$.

Rutizerford and Boltwood, Am. Jour. Sei., 20, 56,$1905 ; 22,1,1906$. 

(10)

suggested that the quantity of radiun emanation associated with one gram of uranium in a natural mineral be used as a standard of radioactivity(l). As only a part of the equlibrium quantity of the radium emanation is retained by the mineral (2) the quantity lost must either be determined and corrected for, or a solution of the mineral must be stored for at least forty days so that the quantity of radium emanation may reach a maximum.

MeCoy, H. N., Phil. Mag., 10, 176, 1907. MeCoy and Ross, Physic. Rer., 24, 124, 1907. Boltwood, B. B., Am. Jour. Se1., 25, $269,1908$.

(1) Boltwood, B. B., Am. Jour. Se1., 18, 381, 1904; Phil. Mag., 9, 599, 1905.

(2) Boltwood, B. B., Phil. Mag., 9, $599,1905$.

Strutt, R. J., Proc. Royal Soe., 77, $472,1906$. 



\section{(11)}

The various methods of using this emanation stendard will be described below.

The compounds of radium have also been used as standards of activity. The purity of radium chloride or radium bromide can be ascertained by measuring the heat given off spontaleously by a known weight of radium preparation in equlibrium with its products(1). This method has been used extensively by Curie and others (2) but is not generally available both on account of the high cost of radium preparations and of the difficulty of ascertaining the purity of the specimen.

The Röntgen Society has proposed (3) that one milligram of pure radiun bromide be taken as the standard of radioactivity, and that the

(1) Rutherford and Barnes, Phil. Mag., $8,202,1904$.

(2) Curie and Laborde, Comptes rendus, $138,1150,1904$.

Eve and IfeIntosh, Phil. Mag., 14, 231, 1907.

(3) Röntgen Ray Society. Nature 77, 543, 1908. Journal Rontgen Ray Soc. Feb. 1908. 

(12)

ionization due to the gamma rays, after passing through one centimeter of lead be taken as the measure.

The conductivity of gases has been extensively studied (I), the conductivity of the air being used as a standard. It has been shown (2)

(1) Strutt, R. J., Proc. Royal Soc., 68, 126,1901

Thomson, J. J., Proc. Camb. Phil. Soc., $11,505,1902$.

Börnstein, R•, Ber. d. Deutsch Phys.

Gesell., 22, 404, 1903.

Burastead and Wheeler, Am. Jour. Sei., 16, 328, 1903.

Himstedt, F., Ann. d. Physik., 13, 573, 1904;

Ber. d. Naturf. Gesell. Frieburg, 14, 181, 1904.

Blanc, G. A., British Association Reports, Carab., 71, 1904

(2) Elster and Geitel, Ann. d. Physik., 2, 425, 1900; Physik. Z. 2, 560, 1901.

Saake, W., Physik. Z., 4, 686, 1903.

Wood and Camploell, Phil. Mag., 13, 265, 1907. 

(13)

by Elster and Geitel and others that the normal conductivity of air varies at various times during the day, and from place to place so that the air standard is at once excluded in any series of neasurments where accuracy is required.

The activity of many spring vaters and other ordinary materials (1) has been expressed in terms of volts fall of potential of a charged body per hour, without data regarding the electrostatic capecity of the body, or the size of the ressel in which the ionization took place. Since the rate of fall of potential of a charged body is ional to the electrostatic capacity of the system for a constant ionization(2) this system of expressing

(1) Himstedt, F., Ann. d. Physik., 12, 107, 1903; Ber. d. Naturf. Gesell. Freiburg, 13, 101,1903.

Rausek, H. F., Physik. Z., $5,130,1904$.

Costanzo and Negro, Physik. Z., 7, 350, 1906.

Hayek, H. V., Z. d. Ferdinandeums für Tyrol

u. Vorarlburg, 50, 524, 1907 .

(2) Rutherford, E., Radioactivity. 2nd. Edition. Camb. Press., p. 100. 

(14)

the results of radioactive measurraents cannot be used when comparative results are desired.

Numerous results on the radioactivity of water samples, gases, and other ordinary materials (1) have been expressed in the C. G. S.

(1) Gerdien, H., Physik. Z., 4, 632, 1903.

Nache, H., Wien. Ber., 113, 1329, 1904.

Curie and Laborde, Comptes rendus, 138, $1150,1904$.

Fngler and Sieveking, $z$. anorg. Cheme, 53, I, 1904 .

Caraphell, N. R., Proc. Canis. Phil. Soc., 13, 132, 1905; Phil. híag., 11, 217, 1906. fiache and Sravis Riramer, Phyzik. Z, , 7, 617, 1906. Radium, 3, 289, 1906. Sury, Jos., laitt.naturf. Gesell. Freiburg Chera. II, 1, 78, 1906; Chera. Zentral. I, 1282,1907. Koch, K. R., Physik. Z., I, 806, L906; Ber. d. Physik. Gesell., 8, 846, 1900. Henrick, Ferd., Physik. Z., $\underline{8}, 112,1907$.

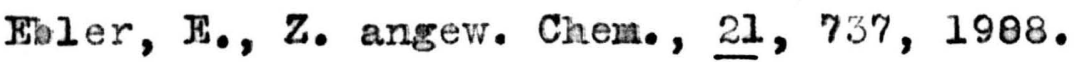





\section{(15)}

electrostatic units. In some cases the size and shape of the testing vessel was given and in others not. This method of expressing the activities was first erployed by Gerdien, then by Mache, and later by Bngler and others (1). This is the method generally employed on the continent of Burope for expressing the activity of the air, water samples, minerals, ete.

Since so many standards of ectivity exist it would seem desireable that we should be able to convert the results obtained, using any one standard, into those of any other standard.

The present investigation was commenced with the intention of comparine the MeCoy uranouranic oxide standard with the Boltwo od emanation standard and with the C. G. S. electrostatic standard. After some three months had been spent in constructing an electroscope and in the preparation of the standards for the coraparison of the McCoy standard with the C. G. S. electrostatic standard McCoy and Ashman published this ratio. (2).They
(1) Loc. eit.
(2) Loc. cit. 

(16)

found the ionization current due to the alpha rays from a thick film of uranouranie oxide was $5.79 \times 10^{-13}$ amperes, or $1.737 \times 10^{-3}$ C. G. S. electrostatic units, per square centimeter. The specific activity of uranium, defined as the total ionization eyrrent from one grara of uramium when all the radiation is absorbed in air, is 796 MeCoy units(1). The total ionization current from one grain of uraniun free from its products is then $4.61 \times 10^{-10}$ amperes or $1.38 \mathrm{C} . \mathrm{G} . \mathrm{s}$. electrostatic units.

Boltwood has shown (2) that if the activity of uranium be taken as 1.00 for his electrscope, that the activity of the radium emanation in equilibrium is 0.62 , that of the radium $A$ is 0.52 , that of the radium $B$ is 0.04 , and that of the radiwa $C$ is 0.91 , or a total of 2.11 tirnes as active as the uramium with which they are in

(1) MeCoy, H. N., Phil. Mag•, 11, 176, 1906. MeCoy and Ashnan, J. Am. Chem. Soc., 29, $1698,1907$.

(2) Boltwood, B. B., Am. Jour. Sci., 25, $297,1908$. 

(17)

equlibrium. Now if the equlibrium quantity of radium eranation from one gram of uramium was introduced into an electroscope, and the equliilbrium amount of radium $A$, radium $B$ and radium C allowed to accumulate, the activity would be $4.61 \times 10^{-10} \times 2.11$ or $9.73 \times 10^{-10}$ amperes, or 2.92

2.2. C. G. S. electrostatic units, if all the alpha partieles had the maximum range in air. In therms of the Boltwood standard the specifie activity of uranium would be $1 / 2.11$ or 0.475 . As has been pointed out above the in* vestigators on the continent of Europe have used the C. G. S. electrostatic standard, while those in England and this country have generally used the Boltwood radium emanation standard. Now MeCoy and Ashman have already (I) determined the relation between thier standard, the Boltwood uraniura oxide standard, and the C. G. S. electrostatic standard. I have calculated above the theoretieal relation which should exist between the Boltwood radium enanation standard and the C. G. S. electrostatic standard.

\section{(1) Loc. eit.}



(18)

Since these last named standards have been used so extensively in the investigation of the radioactivity of gases, waters, roeks, and other common mate ials I have attempted to Investigate the various methods of removing the radium emanation from solution, and to study the relation between these two standards experiaentally, using various forms of electroscopes. The general method of proceedure was as follows:- The electrostatic capacity of the electroscopes was first determined. Definite quantities of the radium emanation were separatdd by the several methods and introduced into the electroscopes. From the rate of leak the current in amperes and C. G. S. electrostatic units was calculated.

\section{Fxperimental Patt. Souree of Radium Fmanation.}

The uranium mineral used as a source of radium emanation was a uraninite of unknown origin purchased from the firm of Eimer and Anend. A large sample, about five hundred grams, which showed no signs of alteration was ground to pass 



\section{(19)}

a brass sieve one hundred and twenty meshes per inch. The sample was then thorghly mixed in order to obtain a perfectly uniform sample.

\section{The Determination of the Uranium}

in the Standard Uraninite.

The analytical determination of the uranitm in the sample of standard uraninite was conducted by slight modifieation of the method deseribed by Boltwood (1). The proeedure was as follows:-

The finely powdered rineral was dimeolved in pure diluted $(1: 1)$ nitric acid. After the first action was orer the solution was eraporated to dryness on the water bath. Two cubic centimeters of concentrated hydrochloric acid were then added and the solution again evaporated to dryness. The residue was moistened with concentrated hydrochloric aeid, and thirty cubic centimeters of distilled water was added. The solution was then heated to boiling and the residue of silica, gangue, etc. was filtered off, and

(1) Boltwood, B. B., Phil. Mag•, 9, 603,1905. 

(20)

and washed with distilled water until free from acid.

The filtrate and washings, which had a volume of about one hundred and fifty cubic centineters were heated to boiling, and hydrogen sulphide (1) passed into the solution for one and a half hours. The brownish black precipitate of sulphides was filtered off and thoroughly washed with hot distilled water. The filtrate was boiled to remove the excess of hydrogen sulphide, and evaporated to a volume of one hundred and fifty cubic centimeters on the hot plate.

The salts in solution in the coneentrated filtrate were oxidized with four cubic centimeters of concentrated nitric acid. About 0.1 gram of microcosmic salt ( sodium ammonium hydrogen phosphate) was added to the solution.

(1) The hydrogen sulphide was prepared from ferrous sulphide and dilute sulphuric acid, and washed by passing through distilled water. 

(21)

which was allowed to cool somewhat, and then poured into a solution of fire grams of anhydrous sodiun carbonate dissolved in bne hundred and fifty cubic centimeters of distilled water, and heated to about fifty degrees Centigrade. The mixture was heated to boiling and boiled ten minutes, cooled to about fifty degrees Centigrade, and ten grams of amonium chloride added. The mixture was again heated andpently boiled for about fire minutes, and then allowed tonstand until cool. The precipitated phosphates were filtered off and washed with distilled water. The filtrate was reserved, and the residue on the filter paper was dissolved in dilute nitric acid in the sarie vessel in which the precipitation took place. The nitric acid solution of the phosphates was again poured into a solution of five grams of sodium carbonate dissolved in one hundred and fifty cubic centimeters of distilled water and treated exactly as in the first case. The precipitated phosphates 

(22)

were then carefully washed and the filtrate and washings added to the first filtrate.

The combined filtrate 5 and washings were boiled in a large casserole until the greater part of the ammonium carbonate was driven off, and the uranium phosphate was precipitated from the solution. Just enough dilute|nitric acid was added to dissolve the precipitate, and the solution was boiled to remove the last traces of earbon dioxide. The solution was then concentrated on the water bath to about fou hundred cubie centimeters, and $0.2 \mathrm{gram}$ armonium phosphate was added. Then ten grams of sodium thiosulphate crystals were added. The precipitate which was fomed was very finely divided, so ten graras of ammonium acetate were added (1). The solution was boiled twenty minutes an the precipitate of sulphur and uranium phosphate, which does not clog the filter paper, filtered

(1) Brearley, H., Analytical Chemistry of Uranium. Longmans, Green and Co., p. 10. 



\section{(23)}

and washed with distilled water.

The filter paper and precipitate wen placed in a platinum erueible and ignited at as low a temperature as possile, until all the carbon was burned off. The residue of phosiphate was then dissolved in the smallest possible anount of hot concentrated nitris acid, and the excess of acid almost neutralized with dilute ammoniun hydroxide. The clear solution was then poured into a solution of three grams of ammonium carbonate dissolved in thirty cubie centimeters of distilled water. A slow current of hydrogen sulphide was passed into the solution for two minutes and the liquid heated cautiously just to boiling. The liquid was allowed to cool and the precipitate which in all cases was very slight was filtered off and washed with distilled water.

In order to see if the precipitate obtained by treatment of the ammonium carhonate solution with hydrogen sulphide contained any uranium, the residue was dissolved on the 

(24)

filter paper by dilute hydrochlorie acid, the acid was nearly neutralized with amonium hydroxide, and potassium ferrocyanide added to the solution obtained. A reddish precipitate would indicate that uranium was present, but in no case was such a precipitate found. The main filtrate was now boiled to remove the excess of amonium carbonate, acidified with dilute nitric acid, and $0.2 \mathrm{gran}$ of aranonium phosphate added. The uranium was then reprecipitated as phosphate by adding ten grans of pure crystalized sodium thiosulphate and ten grams of arraonium acetate. The solution was boiled twenty minutes, filtered, and washed. The residue was ignited in a platinum crueible at a very low temperature until the sulphur was removed, and then at a red heat until all the carbon was burned off. The crucible was then allowed to cool in a desiccator, and weighed. The uranium contained in the green pyrophosphate of uranium thus obtained was calculated on the assumption that the green 



\section{(25)}

sall contained 68.55 per cent of uranium(1), an assumption which has been verified by Boltwood (2).

Three determinations were rade using the air dry uraninite, which gave results as follows:-

0.6830 gram uraninite gave 0.5292 gram freen phosphate of $\mathbf{5 3 . 1 2}$ per cent uranium.

0.2442 gram uraninite gave 0.1887 gram green phosphate or 52.98 per cent uranium.

0.2525 gram uraninite gave $0.1952 \mathrm{gram}$ green phosphate or 52.99 per cent uranium.

Mean of the three determinations on the air dry uraninite/ground to pass a seive one hundred and twenty meshes per inch, 53.03 per cent uranium.

It is well known that the noisture content of finely powdered minerals changes materially. In order to have a check on the moisture content of the powdered uraninite

(1) Brearley, H., Loc. cit.

(2) Boltwood, B. B., Loc. "eit. 

(26)

two samples were weighed out into platinum crueibles, placed in a steam oren, and allowed to remain two hours. At the end of this time they were placed in a desiccator, cooled, and weighed. It was found that,

$0.6830 \mathrm{gram}$ uraninite lost $0.005 \mathrm{gram}$ equivalent to a loss of 0.80 per cent.

0.7368 gram uraninite lost $0.0058 \mathrm{gram}$ equivalent to 0.79 per cent loss.

Two determinations gave a mean loss by heating two hours at one hundred degrees Gentigrade of 0.80 per cent.

The percentage of uranium in the nineral when referred to the finely powdered material heated two hours at one hundred degrees is 53.46 per cent uranium.

The Standard Solutions of Radium

Jrmanation.

This sample of uraninite, carefully standatdized gravimetrically, was used in the preparation of the various solutions of definite content 

of radium emanation.

Fire stock solutions of the standard uraninite to be designated as solutions $\mathrm{A}, \mathrm{B}, \mathrm{C}$, $D$, and $E$ were prepared from four seperate portions as follows:-

A sample of the finely ground material, $1.8860 \mathrm{gram}$, corresponding to one gram of uranium was weighed into a beaker and digested with diluted (1:1) nitric aeid. The solution was heated on the water bath until all the uranium was dissolved and the residue white. One cubie dentimeter of concentrated hydrochloric acid was now added. Bre (1) has shown that when hydrochloric acid is added to a solution of a radium salt that none of the latter is deposited upon the sides of the ressel. The solution was now diluted to about two hundred cubic centimeters, heated nearly to boiling, and filtered. The residue was washed with distilled water, an the combined filtrate and washings transfered to

(1) Ere, A. S., Am, Jour. Sei., 22, 4, 1906. 

(28)

a liter graduated flask, and the volume made up to the mark with distilled water. One cubie centimeter of this solution contained 0.001 gram uranium. This stock solution was known as solution A.

Fifty cubic centimeters of solution $A$ were measured out with a pipette into a fire hundred cubic centimeter graduated flask, and the solution diluted to the mark with distilled water. This solution was designated as solution B. From this solution, one eubie centimeter of which contained 0.0001 gram of uranium, the samples of very small radium content were prepared.

Solution C was made up three weeks later

from a new portion of 1.8860 gram of uraninite, in exactly the same manner as was solution $A$. One cubic centimeter of solution C contained 0.001 gram uranium.

Solution D was made up in a very similar manner. A sample of the uraninite, 3.7720 grams, was weighed out into a beakep and dissolved in 

(29)

diluted (1:1) nitric acid. The solution was diluted to about two hundred cubic centimeters and filtered. The residue was washed with distilled water, and two cubic centimeters of concentrated hydrochloric acid added to the combined filtrate and washings. The solution was boiled fifteen minutes in order to completely remove all the radium emanation present in the solution. The time at which the boiling was discontinued was noted, in order to calculate the quantity of radium enanation that would accumulate during storage of the sample. The solution was then transfered to a liter graduated flask and the volume up to the mark with distilled water. One cubic centimeter of solution D contained 0.002 grara uranium.

Solution $\mathbf{E}$ was made up aloout two hours later in exactly the same manner as solution $D$, using another portion of 3.7720 gram uraninite. One cubic centimeter of solution $\mathrm{E}$ contains 0.002 gram uranium. 

(30)

Storing of the Standard Samples,

Sereral forms of apparatus have been used for storing samples of material containing radium salts in solution. The most senerally used of these consists of a flask fitted with a tightly fitting rubber stopper. (1) When the emanation is to be boiled off the stopper is removed and the flask attatched to the collecting apperatus very quickly in order to arole 10 ss of the radium emanation as much as possible. sepraration

Schlund and Moore (2) have studied the to of radium emanation from mineral water. They found that the quantity of radiwa emanation lost by these solutions of very small content of the emanation when heated to ninty fire de-

(1) Sehlundt and Moore, Jour. Prys. Chem., 9, 320, 1905. Strutt, R. J., Proc. Royal Soc., 77, 472, 1906

(2) Schlundt and Moore, Jour. Phys, Chent, 8, 320, 1905. 

(31)

grees Centigrade, was small ( thirteen per cent). The concentration of radium emanation In the solutions studied was rery much greater and it was desired to aroid any loss which might possibly occur during the change of stoppers. After several trials with other forms, the two forms of storage flasks shown in the photograph (Fig. 1) were devised and adopted. Numer I, on the left, consisted of a two hundred eubic centimeter Frlenmeyer flask (A) fitted with a two holed rubber stopper (B). one of these holes was plugged with a piece of glass rod. (A one holed rubber stopper is much to be prefered.) The other hole was fitted with a short piece of glass tubing (c) about six centimeters in length. The lower end of the glass tube (C) was just flush with the lower end of the rubber stopper (B). The upper end of the tube was fitted with a piece of rubler tubing (D) about six centimeters in length, closed by means of a screw elip (F) elamped tightly over the rubber tube just at the end of 

(32)

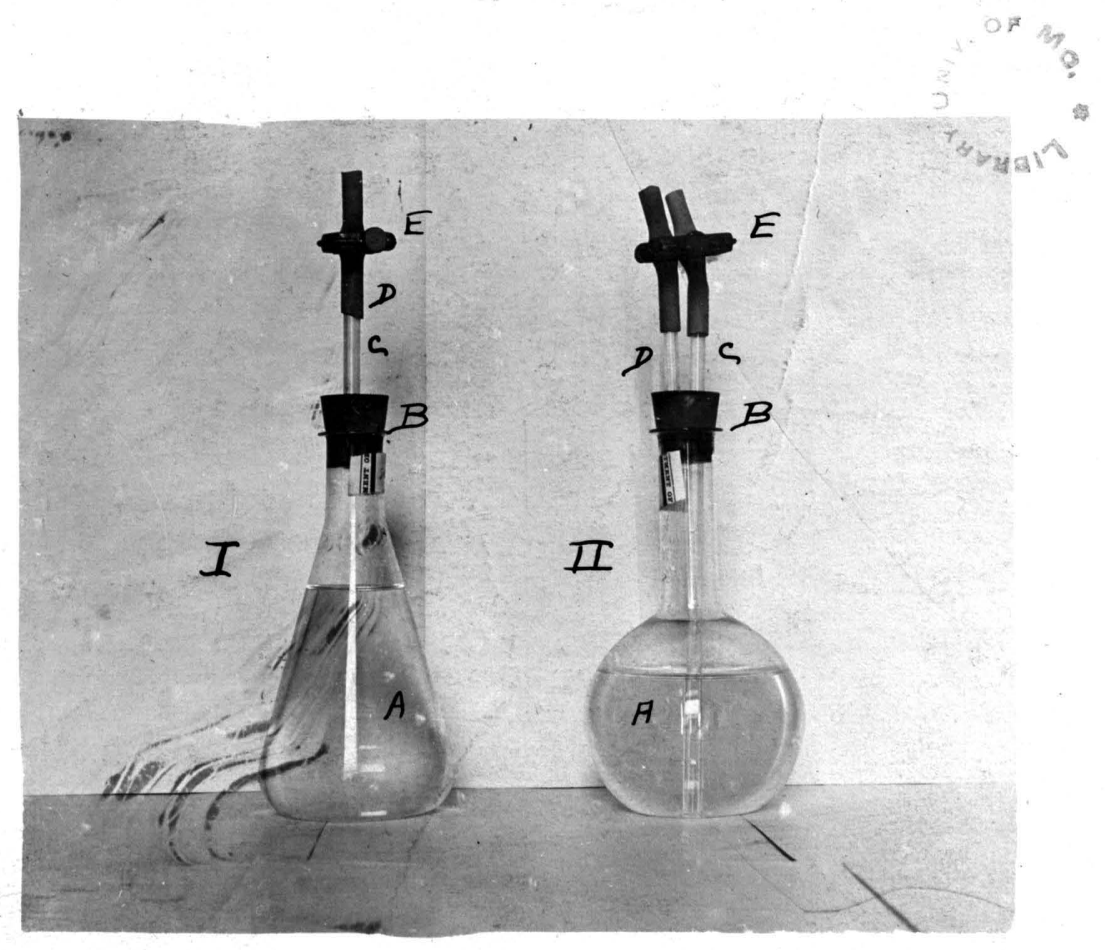

Fig. 1. Storage Flasks. 



\section{(33)}

the glass tube in order to aroid diffusion of the emanation through the rubber tube as much as possible. This design of storage flask was used for storing the ${ }_{\wedge}$ samples prepared from stoek solutions $A, B, C$, and F. It proved rery conrenient for attatching to the rarious forms of apparetus for separating the radiun emanation which are described below, and entirely obriated any loss of the emanation due to the change of stoppers as in the former arrangements.

Numer II, on the right (Fig. 1), differs only slightly from the design just deseribed. It consistapf an ordinary flask of about two hundred and fifty cubic centimeters capacity (A) fitted with a two holed rubber stopper (B). Into one hole of the stopperwas fitted a ptee of glass tubing (C) five millimeters in diameter whloh extended to the bottom of the flask. The other hole of the rubber stopper (B) was fitted with a short piece of glass tubing (D) the lower end of which flush with the lower end of the stopper. The upper ends of the glass tubes were 

(34)

fitted with short piees of rubber tubing, and elosed by means of the large screw clip (E). By making the two glass tubes extend the ame distance above the stopper one screw clip served to completely close both openings. This form of storage flask was used for storing the samples which were prepared from solution $D$, and from which the radium emenation was remored by means of the apparatus employed hy Boltwood (1) a detailed description of which is given under the section deseribing the forms of apparatus for remoring radium emanation. Fileven sets of samples, eighty in all, containing from $0.001 \mathrm{gram}$ to $0.3 \mathrm{gram}$ uranium were prepared from the stdndard stock solutions and stored in the flasks just described. The samples from solutions A, B, C, and $E$ were stored in the first described form of flask, suffieient distilled water being added to

(1) Boltwood, B. B., Phil. Mag., 9, $599,1905$. 

(35)

fill the flasks to within alout six centimeters of the bottom of the stopper. The samples from solution $D$ were stored in the flasks of the second design. The contents of the flask were diluted so that the solution filledabout two thirds of the flask.

The quantity of radium emanation in equlibrium with radium at tains its maximum value after the lapse of about a month.(1) The samples prepared from solutions A, B, and C were all stored orer six weeks before they were boiled off, so that the quantity of radium emanation in these sample ofnumbers $1 \mathrm{~A}$ to $46 \mathrm{C}$ inelusive, reached ita maximum. The samples from solutions $D$ and $\mathbf{I}$ were not stored for a suffleient time to allow the equlibrium amount of the radium emanation to be formed. Under these cireumstances the sample was stored at least four days. The time at which the sample was prepared was known

(2) Rutherford, F., Radioactivity, 2nd. Edition. p. 372 . 

(36)

and the time at which the separation of the emanation was completed was noted. From the interral $t$ in hours the quantity of radium emanation which had aceumulated was calculated according to the following equation:- (1)

$$
\begin{aligned}
& \frac{I_{t}}{I_{0}}=1-e^{-\lambda t}, \text { or } \\
& I_{t}=I_{0}\left(1-e^{-\lambda t}\right) .
\end{aligned}
$$

where $I_{t}$ is the quantity of exanation which would accumulate in $t$ hours. I is the maximum, or equlibrium arnount, and $\lambda$ is the radioactive constant of the radium emanation. The value of $\lambda$ was taken as 0.00744 (2).

\section{Apparatus for Boiling off}

the Radium Franation.

Inasmuch as a number of different forms

(1) Rutherford, E., Radioactivity, 2nd. Edition, p. 372 .

(2). Boltwood, B. B., Phil. Mag., \&, $599,1905$. 

(37)

of apparatus have been devised and used by different investigators for separating radium from solutions of radium salts, it seemed desirable to study the relative effieieney of the more common forms. In all, fire types of apparatus were used, and these will now be deseribed In the order of thier adoption during the progress of the inrestigation.

The strutt Apparatus. In the original strutt apparatus (1) It is possible that some of the emanation contained in the receiver will not be introduced into the electroseope on account of the trapping of some of the gas in the connecting tubes. Also the operation of diseontinuing boiling is rather diffieult. tracefoce

The original design was, slightly changed so as to aroid the trapping of any gas in the connecting tubes, and also to simplify the manipulation connected with the stopage of the boiling. The

(1) Strutt, R. J., Proc. Royal Soe., 77, 472, 1906 

(38)

Improved apparatus is shown in figure two.

The storage flask (A) shown also in figure one was attatched to the reflux condenser (F). The condenser was attatehed in turn to the three way stop cock $(G)$. The three way stop cock could connect the receiver (I) with the condenser (F), shutting off at the same $\wedge$ communication with the outside air through the side tube (H). Or by a quarter turn it will eut off the receiver (I) and connect the condenser (F) with the air through (H). By another quarter turn the whole apparatus could be placed in communication with the outside air. The receiver (I) was connected with the leveling bulb (J) by means of the rubber tube (K), which connection could be closed by means of the screw clip (L). Comaunication vith the electroscope was made through the side tube (M) and the glass stoppered U-tube (N) containing concentrated sulphuric acid and fless wool.

The manipulation of the epparatus for the separation of the radiun emanation from the solution in the flask (A) was as follows:- 

Fig. 2. The Strutt Apparatus.

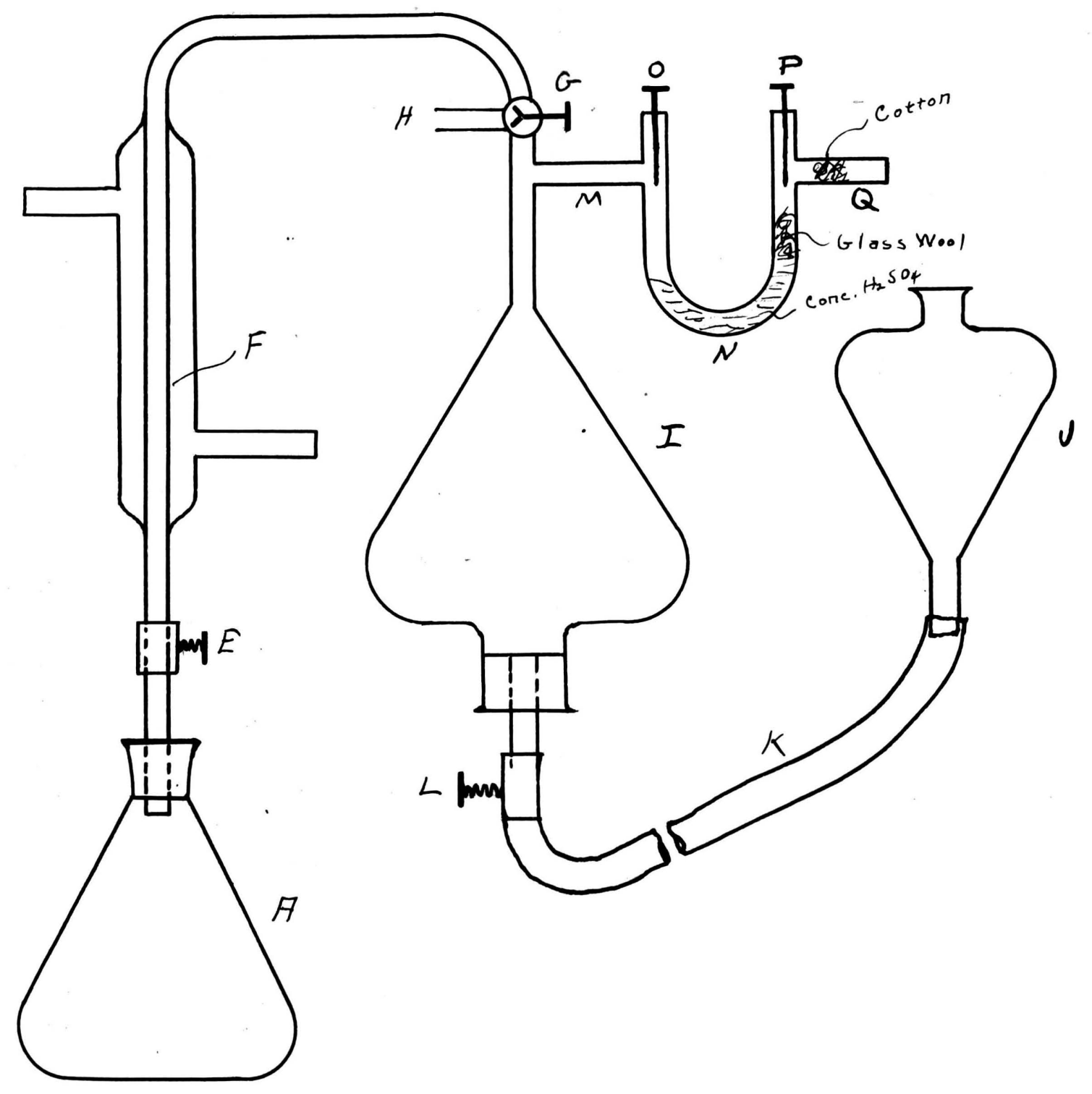



(40)

The stop cock (P) of the U-tube (N)

was closed. The three way stop cock (G) was turned to thefirst position, or so that it connected the receiver (I) with the condenser and cut off the comaunication with the oubside air through (H). The stop cock (P) was then opened. The receiver (I) and the leveling bulb (J) were filled with distilled water and the level adjusted so that the water filled the receiver to the lower egge of the branch tube(M). The screw clip (L) and the stop cock (P) were then closed. The screw elip (L) was now opened and the leveling bulb $(J)$ lowered in order to test for possible leaks. If the apparatus was tight the serew clip ( $\mathbb{E}$ ) was opened. A slow current of water was kept running through the jacket of the condenser(F). The contents of the flask (A) were heated to boiling and kept in rapid ebullition for a least twenty minutes, when the water was turned off, and that in the jacket of the condenser allowed to run out. It was fand nescessary at intervals during the boiling to 



\section{(41)}

remove the flame in order to allow the condensed steam in the condenser (F) to flow leack into the flask (A). After the steam had swept out all the gases in the condenser over into the collection receiver (I) the three way stop cock (G) was turned to the second position, or so that the receiver (I) was cut off, and the Flask (A) placed in commication with the outside air, after which the boiling was discontinued. The operation up to this point results in separating the emanation accumulated in the solution in the flask (A) and storing it in the receiver III.

$$
\text { the intioduction inch the etectroserpe of }
$$

In order to avoid thorium emanation and its disintegration products, the gas was stored in the receiver (I) for at least twenty minutes before it was introduced into the electroscope. In order to transfer tho onenation, now stored in the receiver (I) into the electroscope, the eacter t was partially exausted by means of water suction. The exasuted electroscope was now connected to the U-tube (N) by means of a piece 



\section{(42)}

of heavy rubber tubing. As an extra precaution to aroid any sulphuric acid being carried over into the electroscope a plus of cottion was placed in the side tube at (Q). The brass stop cock of the lectroscope was opened, then the stop cock (P) of the U-tube very slowly so that about five bubbles per second passed through the sulphuric acid. When the level of the water in the receiver (I) reached the lower egge of the side tube (M), the serew clip (L) was closed and the three way stop cock (G) turned to the third position or so that the whole apparatus was connected with the outside air. After the connecting tubes had been swept free of the emanation by means of the current of air, and the pressure in the electroscope had risen to nearly that of the atmosphere the stop cock of the electroscope was closed and the U-tube disconnected. The pressure in the interior of the electroscope was equalized with that of the atrosphere y opening the stop cock for an instant when it was closed. 

(43)

Schlundt and wo ore Apparatus. The second form of apparatus was essentially that deseribed by Schlundt and Woore (1). It consisted of a gas burette (H) (Fig. 3) provided with a stop cock (I) and a leveling bulb ( $J$ ). The storage flask (A) described above (2) was attatched to the branch tube (K). This is the apparatus essentially as described(3), but the introduction of the emanation without trapping some of it in the connecting tubes was rether difficult. The apparatus was therefore modified with a view of obviating this difficulty. A T-tube (Nav) was sealed on just above the stop cock (I). A stop cock (Q) was sealed to the end (II) of the $T$-tube, and to the other end (N) a glass stoppered U-tube, containing concentrated sulphuric acid and a plue of glass wool was

(1) Schlundt and Moore., Jour. Phys. Chem., 9, 320, 1905.
(2) Iloid. $p, 31$.
(3) Schlundt and Moore, Loc. cit. 

(44)

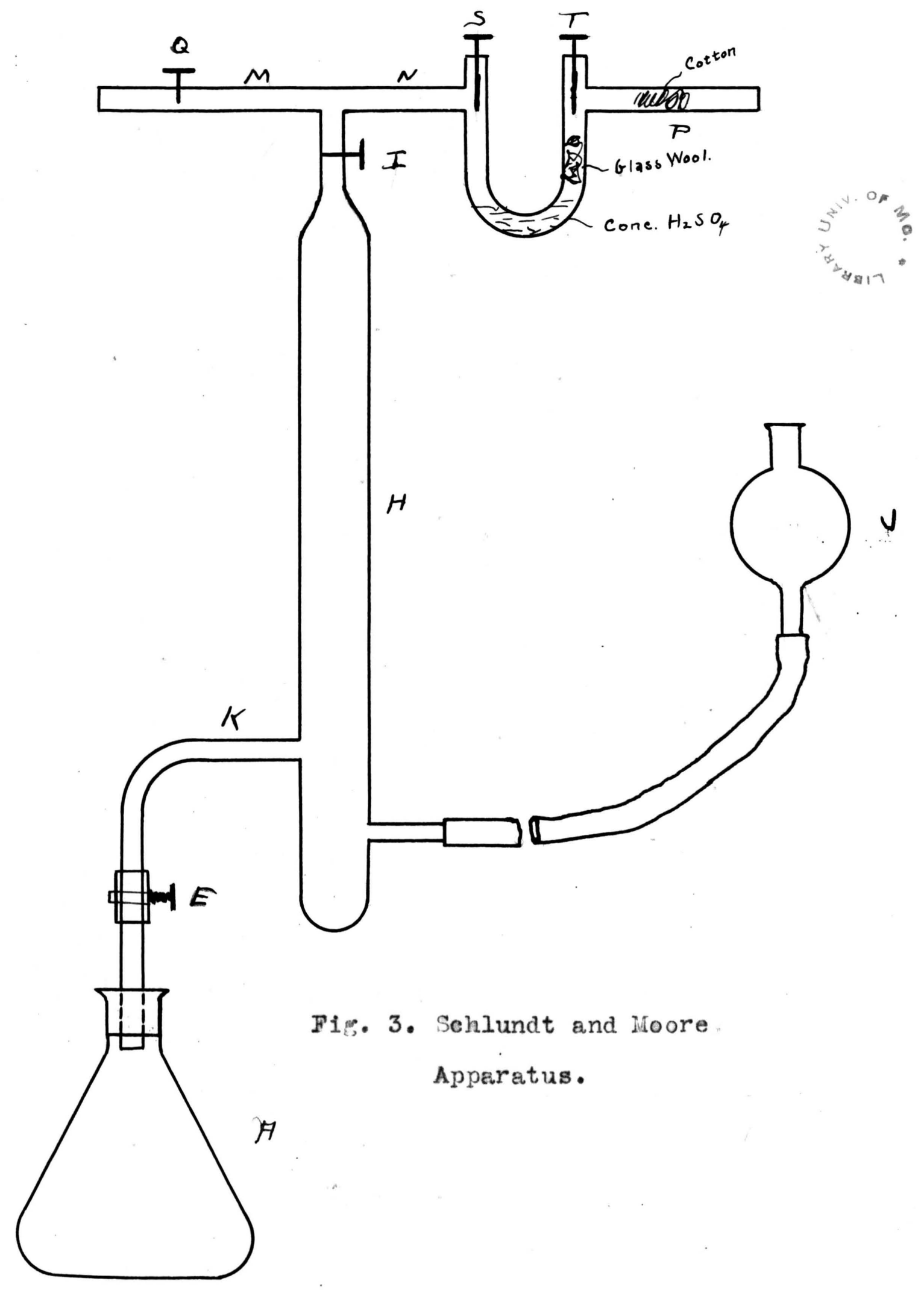



(45)

was attatched means of a short piece of rubber tubing. The branch tube of the U-tube carried a plug of cotton at (p).

The manipulation of this apparatus was coraparatirely simple but required close attention. After connecting the storage flask (A) to the side tube (K) of the burette, the burette and leveling bulb were filled with distilled water to the bottom of the stop cock (I). The leveling bulb (J) was now lowered so as to bring tine cont tents under a slightly reduced pressure. In this way any small leak which might occur would be inward and no loss of emanation would occur. The screw clip (F) was then opened and the solution in the rlubk (A) olled from twenty to thirty minutes: At intervals during the boiling the flame was withdrawn and the water from the burette allowed to fill tine flask. In this way the greater part of the water through which the emanation had bubled was boiled. This operation minimized the 10ss of emanation by absorption in the water in the burette (H). 



\section{(46)}

The separated gases vere allowed to stadd in the burette for at least twenty minutes before being introduced into the electroscopes. The thanfer of gas with this form of apparatus was a very simple matter. The stop cock (Q) vas closed and the $U$-tube connected to the partially exausted electroscope. The stop cock of the pantwely examstad electroscope was then opened, and then those of the U-tube (S) and (T) were opened very slowly, and the pressure inside the drying train allowed to become equal to that in the eleetroscope. The stop cock (I) was then opened and the gas allowed to pass into the electroscope at the rate of about five bubbles per second. When the level of the water in the burette reached the level of the branch of the T-twoe the stup cock (I) was closed and the suop cuck (Q) slowly opened so that a slow current of air would steep any gas in the connecting tubes over into th electroscope. When the pressure|in the interion of the apparatus had nearly reached that of the atrosphere the stop eock of the elec- 



\section{(47)}

troscope was closed, the apparatus disconnected, and the pressure equalized by opening the stopcock for an instant.

Sehlundt and Hoore Apparatus for Water Samples. This form of apparatus used by Echlundt and Moore for the separation of radium emanation from large volumes of solution (x) such as water samples is shown in figure four. The apparatus consisted of a large Liebig condenser (H) about sixty centimeters in length. It was fitted with a one holed rubber stopper through which a glass tube about fifteen centimeters in length extended about ten centimeters into the inner tube of the condenser. The lower end of the tube was connected with the usual storage flask (A). To the inner tube of the condenser a side tube (J) was fused, which connected with the tubulated leveling bottle (K) by reans of a piece of ruber tubing

(1) Schlunt and Moore., Jour. Phys. Chem., 9, 320, 1905 . 



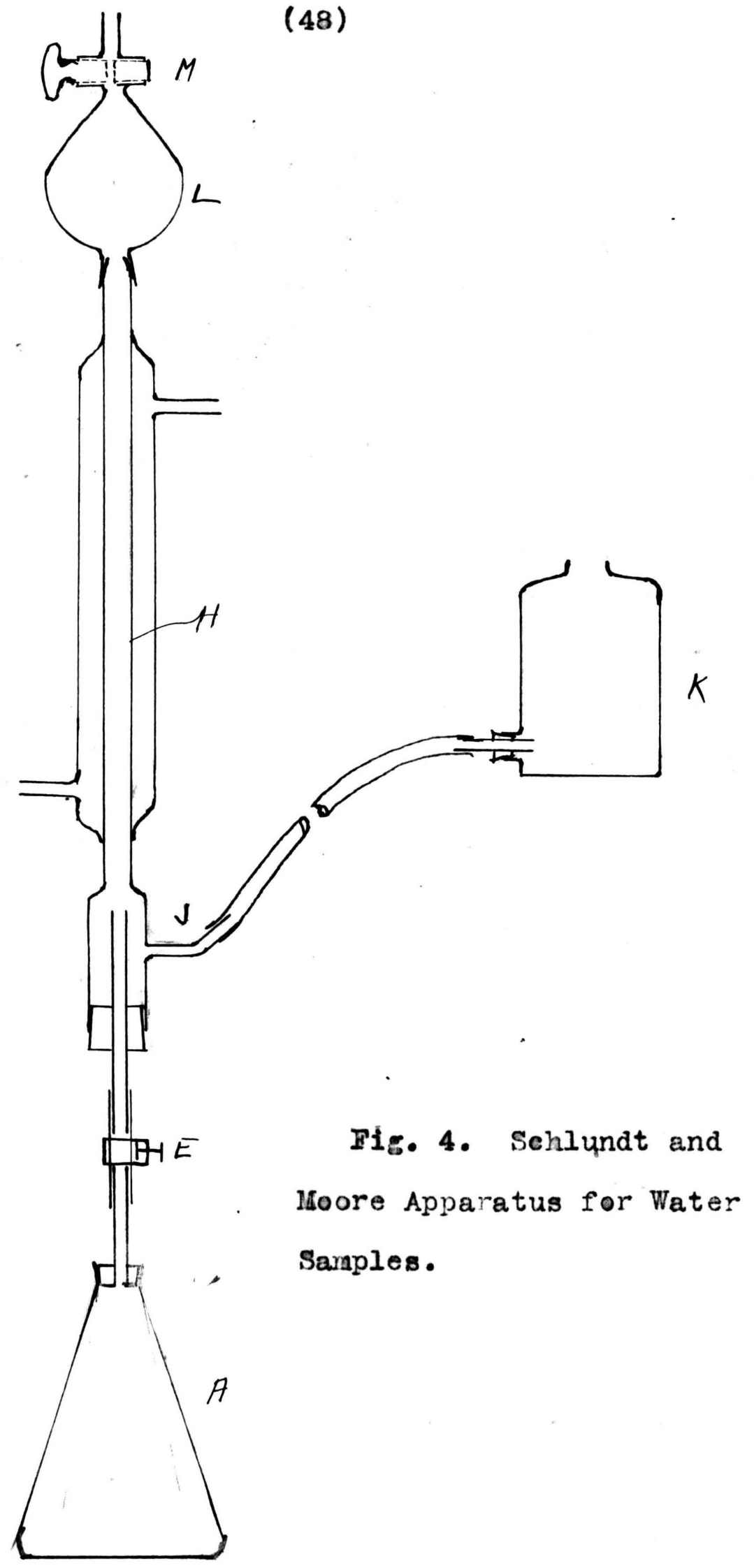



(49)

about one meter in length. A short piece of rubber tubing about two centimeters long was slipped over the tapering end of the condenser (H), over which a separating funnel (L) of one hundred and fifty cubic centimeters capacity was placed. The ster of the separating funnel whas cut off about five centimeters above the stop cock (M). The operation of separating the emanation was carried out as follows:-

The stop cock (II) was opened and the whole apparatus filled with distilled water. Fnough water was placed in the leveling bottle (K) to corer the opening to a depth of about two centineters. The stop cock (II) was now closed and the leveling bottle (K) lowered so as to put the contents under a slightly reduced pressure. The serew ellip (E) was then opened and the contents of the flask (A) heated to boiling. The erolved gases collected in the bulb (L). the boilin; was continued for at least twenty minutes, and until the funnel and condenser tube were 

(50)

completely filled with gas and steam. On account of the small volume of the rlask (A) it vas un-. nescessary to run water through the jacket of the condenser.

For transferring the gases to the electroscope a small drying train similar to that described on the apparatus of Schlundt and Moore (1) was used. This same form of drying train was used on three forms of apparatus, the Schlundt and Moore apparatus for water samples here described, the Boltwood apparatus, and the MeCoy apparatus both of which will be described later. In use it entirely avoids any trapping of gas in the drying train, and makes the operation of transfering the gas to the electroseopes a very simple matter.

$$
\text { It consisted of a U-tube (A) (Fig. 5) }
$$
containing a little concentrated sulphurie acid, and with one limb plugged with glass wool. In the side tube (B) a plug of cotton was placed. To the other limb a T-tube (c) was sealed. The

(1) Ibid. p. 43 . 

(51)

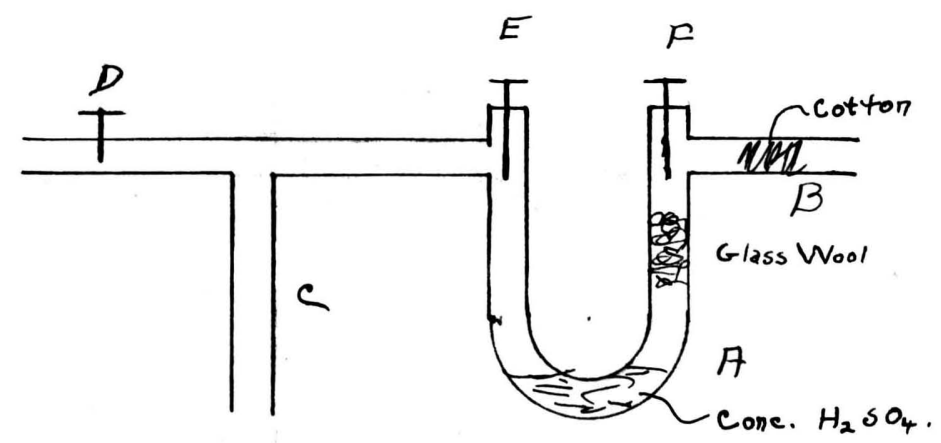

Fig. 5. Drying Train. 

(52)

open end of the straight pottion of the T-tube was closed by means of the stop cock (D). The branch of the $T$-tube was attatched to the burette by means of short peice of rubber tubing: In use the side tube (B) was attatched to the exausted ressel ( in this investigation the electroscopes) and the pressure reduced to that of the vessel by opening the stop cock of the vessel and then the glassptop cocks (E) and (F). The stop cock of the burette was now opened and the gas allowed to flow into the ressel at the rate of five bubbles per second. The sulphuric acid in the U-tube served two purposes, first to dry the gas, and second to give the rate of flow and so avoid extreme disturbance of the leaf system of the electroscopes. When the level of the water reached the top of the branch of the T-tube the stop cock of the burette was closed, and the etop cock (D) opened so that a slow current of air would sweep any emanation in the arying train over into the electroscope. The apparatus was disconnected exactly as was the 

(53)

Schlundt and Moore apparatus described above. The Boltwood Apparatus. The Boltwood apparatus used was essentially that deseribed by Boltwood (1) for the collection of the radium emanation occluded in minerals. The samples to be boiled off in this form of apparatus were stored in the secone form of storage flask(2). A fire hundred cubic centimeter flask (G) half filled with distilled water was connected y means of a glass tube to the longer tube of the storage flask (A) (Fig. 6). This tube had a branch at (H), to which was attatched a short peice of rubber tubing closed by the screw clip (I). The flask (J) which had a capacity of fifteen hundred cubic centineters was filled at the beginning of an experiment with a dilute ( one per cent)

(1) Boltwood, B. B. Am. Jour. Sei., 18, 380, 1904; Nature 70, 80, 1904; Phil. Mas., 9, 599, 1905 .

(2) Ibid. p. 33. 

(54)

Fig. 6. The Boltwood Apparatus.

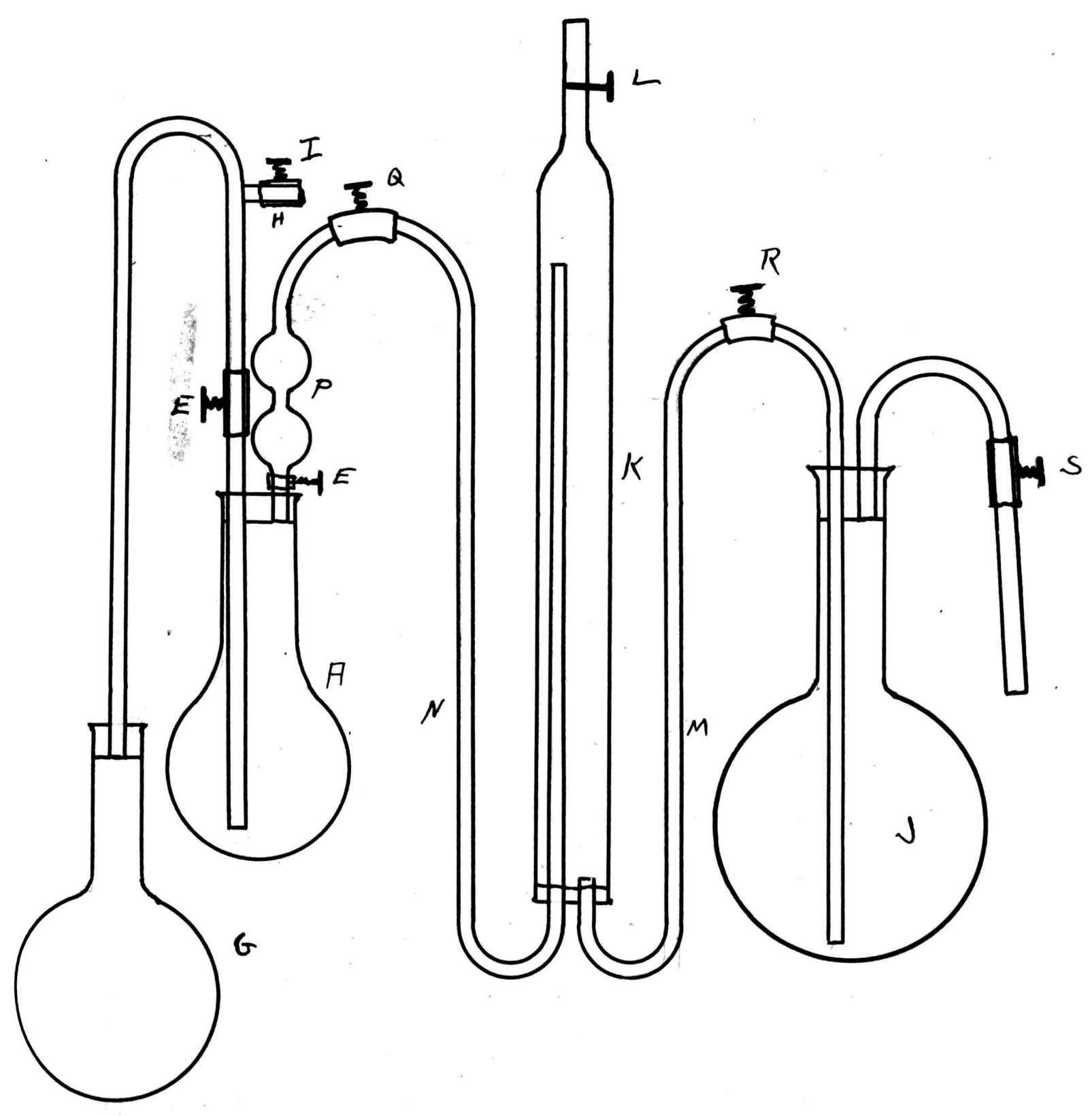



(55)

boiling solution of sodium hydroxide. The burette (K) consisted of a piece of wide glass tubing, drawn out at the upper end and closed with a peice off rubber tubing and serew clip (L). The lower end of the burette was closed by means of a two holed rubber stopper. The tube (M) was bent so as to connect with the flask (J). A rubber joint and screw clip (R) permitted of detatehing the burette frora the flask ( $J$ ) for convenience in carrying the burette containing the separated water gases. The tube (N) extended nearly to the top of the burette and connected with the bulbs (P) by means of the rubber tube and screw clip $(Q)$. The bulbs (P) were connected to theshort tube of the storage flask (A). The operation of collecting the gases was as follows:-

The sodium hydroxide solution in the flask $(J)$ was heated to boiling. By elosing the screw clip (s) the bolling solution of sodiun hydroxide would be foreed over into the burette (K). When the burette was filled the screw clip 

(56)

(L) was closed and the screw clip (S) opened. The water in the flask (G) was boiled rigorously, and when the stean was issuing freely from the side tube (H) th screw clip (I) was closed and the screw clip (E) was opened at once. The serew clips $(Q)$ and $(R)$ were open. The solution in the flask (A) was kept boiling until all evolution of permanent gases ceased, which usually required about twenty minutes, after which the screw clip (Q) was closed and the screw clip (I) quickly opened to avoid the cork in the flask (G) blowin out. The introduction of the gases was not found so simple as in the apparatus of Schlundt and Moore described above. The screw clips $(Q)$ and $(R)$ were elosed, and the burette detatched from the remainder of the apparatus. The drying train previously deseribed was connected to the upper end of the buette (K). A glass tube the end of which dipped below the surface of some water in a beaker was attatched to the tube (N). A similar tube 



\section{(57)}

and beaker were attatched to the tube (M). The drying train was connected to the electroscope and the pressure in the tubes reduced as explained (I). The stop cock (L) was then opened, then the screw clip (Q) very slowly until all the gas in the tube (N) was replaced by vater. The screv clip (Q) was then closed and the screw clip (R) opened slowly. From this point on the method was exactly as described in the former case.

The MeCoy Apparatus. The MeCoy apparatus was the, simplest studied (2). The flask (H) of about fifteen hundred cubic centimeters capacity (Fig. 7) was fitted with a two holed rubber dtopper. A glass tube (J) lead from the bottom of the flask to the beaker (I). A piece of glass tubing about six eentimeters long was provided with a peice of rubber tubing and a screw

(1) Tbid. p. 52.

(2) MeCoy and Ross, Jour. Am. Chem. Soe., 29, 1700,1907 . 

(58)

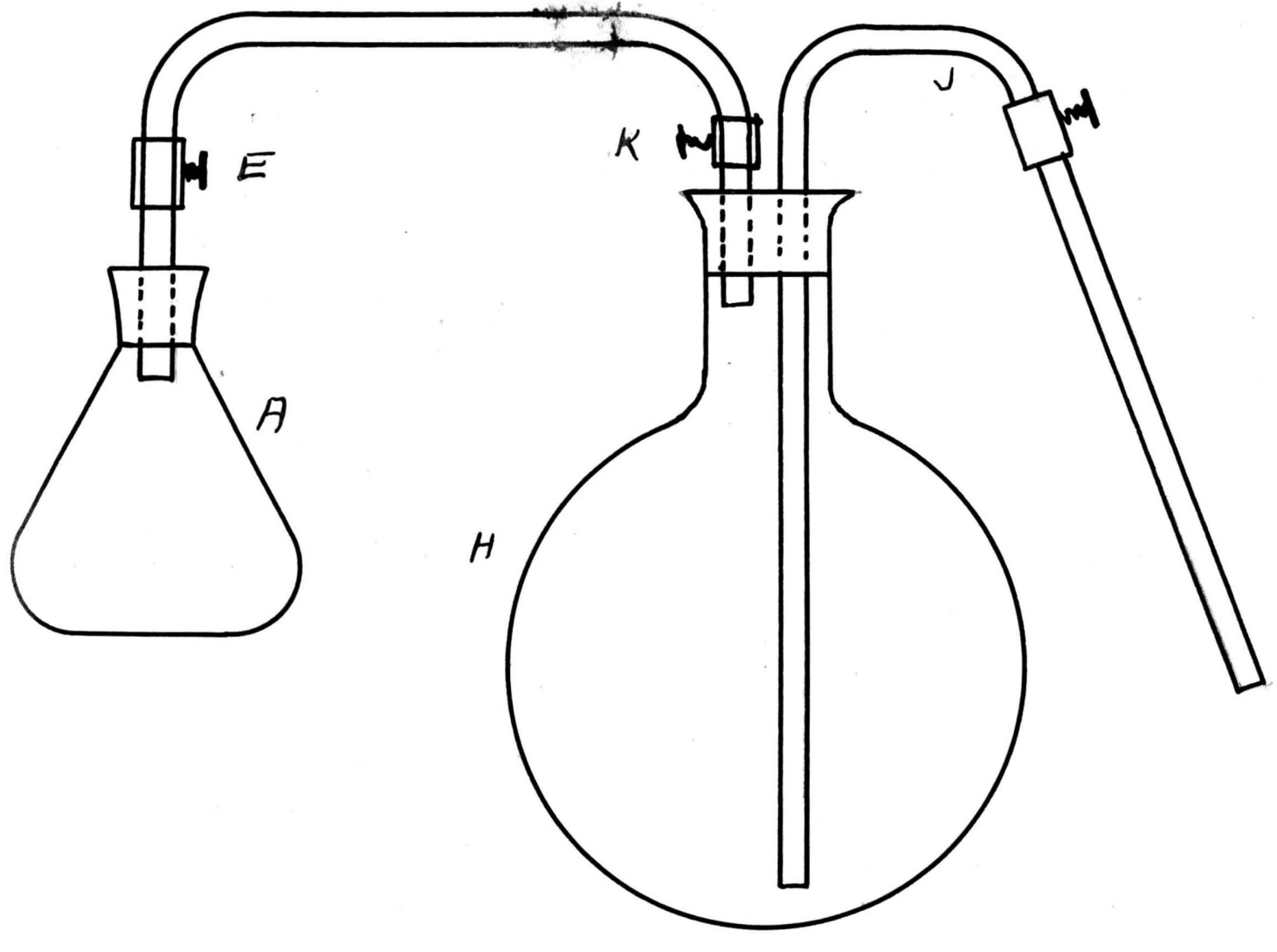

Fig. 7. The MeCoy Apperatus. 

(59)

elip (K) and inserted in the other hole of the stopper so that the lover end of the tube was flush with the botton of the stopper. A U shaped glass tube connected the storage flask (A) with the short tube. The manipulation was very simple. The flask (H) was filled with boiling dilute (one per cent) solution of sodiun hydroxide, and the beaker one third filled with distilled water. The serew clips (K) and (F) were opened and the contents of the flask (A) boiled for at least twenty minutes. When most of the sodium hydroxide solution in the flask (H) had been displaced the screw clip (K) was closed and the flask (A) quickly disconnected. After standing twe nty minutes, the drying train for tramsfer ing the gas to the electroscope was conneeted and the gas transfered as deseribed above. Another form of apparatus for separatuing radium emanation from its aqueous solutions should be mentioned. It was designed and used by boddy and Mackenzie for the 

(60)

accurate estimation of small quantities of radium emanation contained in minerals. The emanation was removed from the solution of the mineral to be tested by boiling in vacue. The gases were passed through phosphorous pentoxide and collected over mercury. The gases were then expelled into an electroscope. (1). This method is probably the most accurate for separating the emanation, but the nescessary apparatus was not arailable for these experiments.

Besides studying the separation of radium emanation from aqueous solutions, some experiments were conducted to determine ${ }_{1}$ the quantity of radiwa oc cluded in the standard uraninite. The apparatas differed only slightly from the Schlundt and 1foore apparatus described above. (2). The Schlundt and Moore form of burette was used. The sample of finely powdered uraninite

(1) Soddy and Machenzie, Phil. Mag., 14, $272,190 \%$.

(2) Irid. p. 43 . 

(61)

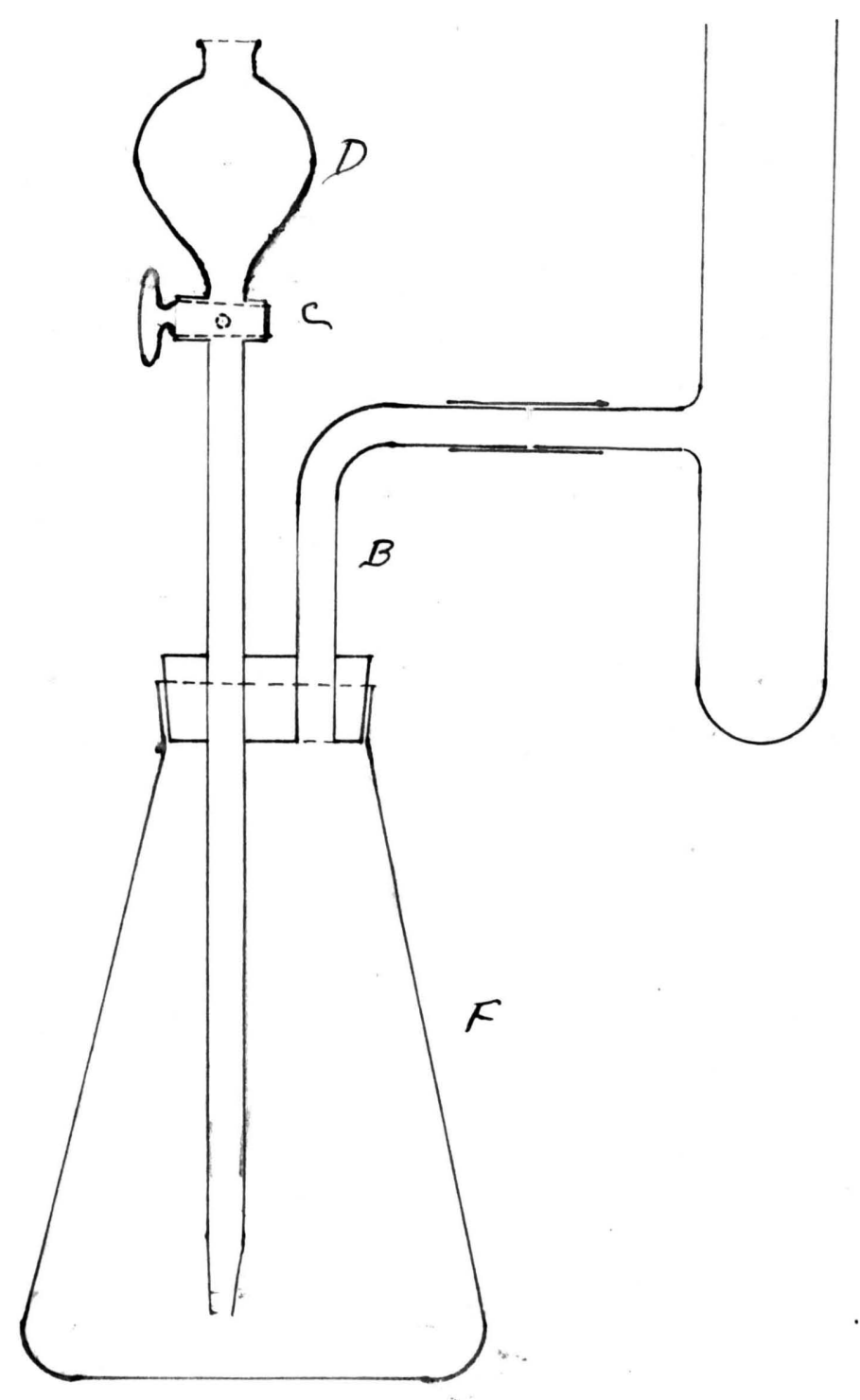

Fig. 8. Apparatus for Separating Radium Thanation Occluded in Soluble vinerals. 

(62)

about 0.1 cram was weighed out into the fifty eubic centimeter flask (F) (Fig. 8.) The flask (X) was provided with a dropping funnel (D) and delivery tube (B). It was then connected with the side tube of the burette exactly as was the storage flask (A) (Fig. 3). The burette was filled with dilute one per cent solution of sodiun hydroxide and the stop cock (I) of the burette closed. The dropping funnel (D) Fig. (8) was filled with diluted (2:I) nitric acid. The leveling reseroir of th gas burette was lowered below the lerel of the aeid in the funnel (D). Then by opening the stop cock (C) about fifteen cubic centimeters of the diluted acid were introduced. The stop cock (C) was then closed and the flask neated cently until all the uraniun in the uraninite had dissolved and the residue was white: If any gas collected in the stem of the funnel during this operation It was displaced by water introduced through the funnel. By withdrawing the flame suffieient witer was allowed to flow foom the burette into 

(63)

the flask to continue the boiling for affeast twenty minutes, or until all evolution of permanent gases had ceased. After storing twenty minutes the gas was transfere to the electroscopes as deseribed abore. This apparatus has been used by Boltrood, and by Sellund and Moore in standardizing thier electroscopes( 1 ).

\section{The Flectroscopes.}

since the object of this investigation was partially to ascertain if results expressed in terms of the Boltwood emanation standard could be converted into C. G. S. electrostatic units for different electroscopes, several of the standard forms used by different investigators were constructed and used. The differeqt insturments employed will now be described. Flectroscope Number 2. This eleet-

(1) Boltwood, B. B., Loe, Cit. schlundt and Moore, Loc. Cit. 



\section{(64)}

roscope was essentially the Boltwood modi-

fication of the C. R. T. Filson electroscope.(1)

It consisted of a rectangular brass frame

$15 \times 10 \times 5$ centimeters.(Fig. $)$. Small strips

of brass (s) $3 \times 3$ millimeters were soldered

on the inside of the frame, about four milli-

meters from the edges. Two peiees of plate

glass six millimeters thick were rounted in

the recesses thus formed on theffront and back

of the frame.

The method of mounting these glass

plates so as to make air tight joints is

of particular importance. Boltwood (2)

used hot sealing wax, and marine glud and

plecein (3) have been used in this laboratory

to some extent, but all of them up to this

time have presented some difficulty in securing
(1) Boltwood, B. B., Loc. Cit.
(2) Boltrood, B. B., Loc. Cit.
(3) welter, B.; Ann. d. Physik., 18, 860, 1905. 



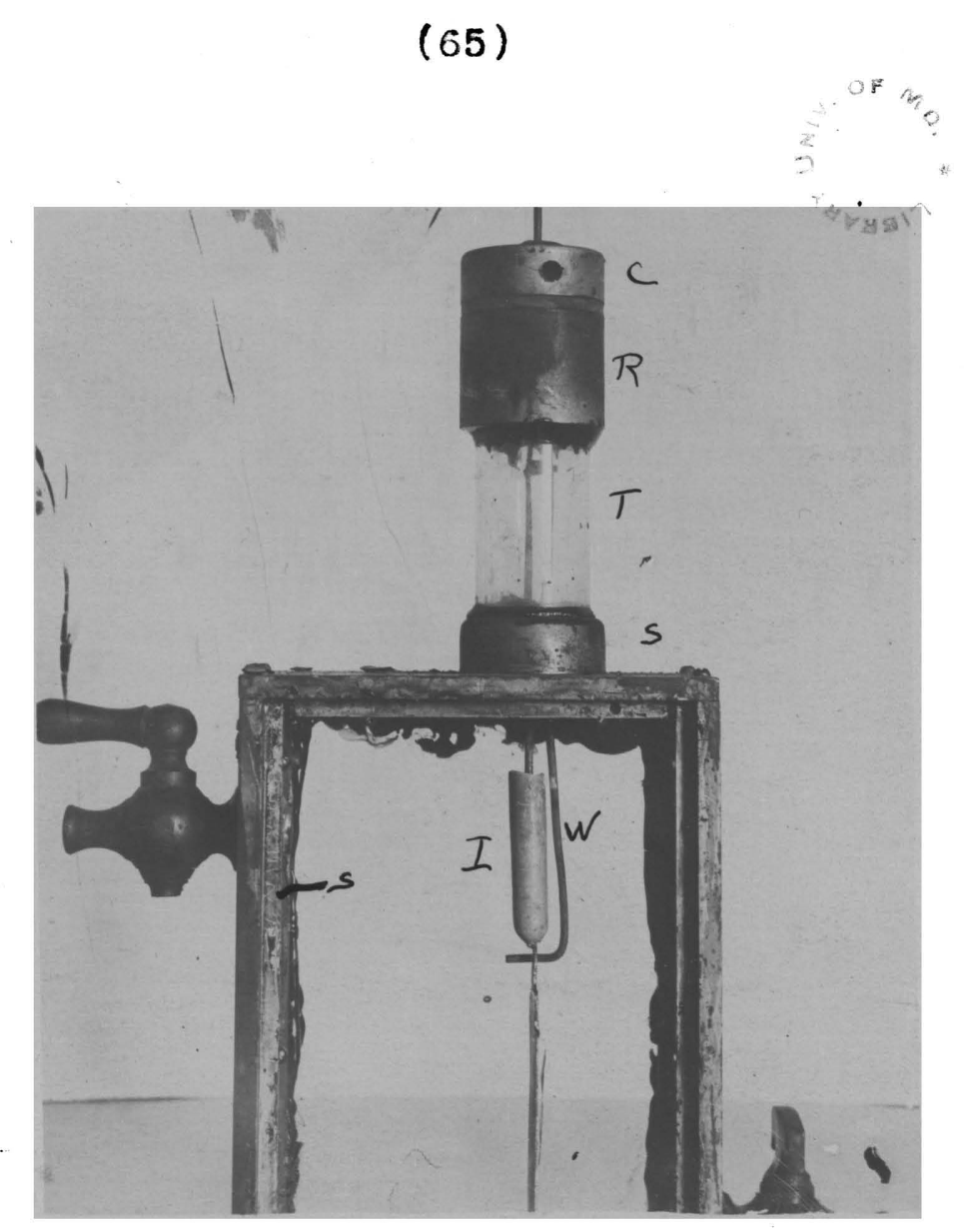

Fig. 9. Electroseope No.2.

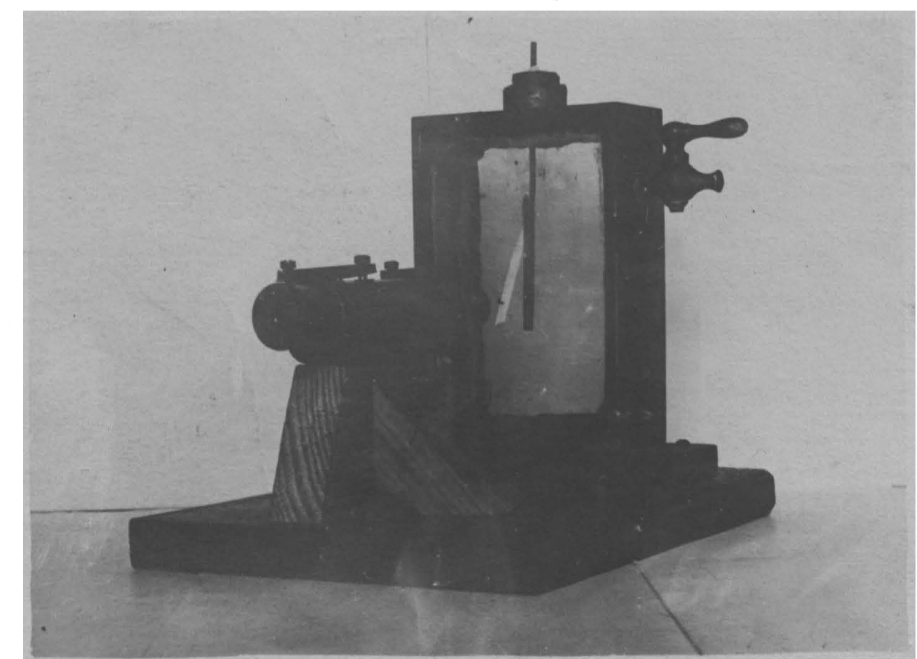

Fig. 10. Electroscope No. 8. 

(66)
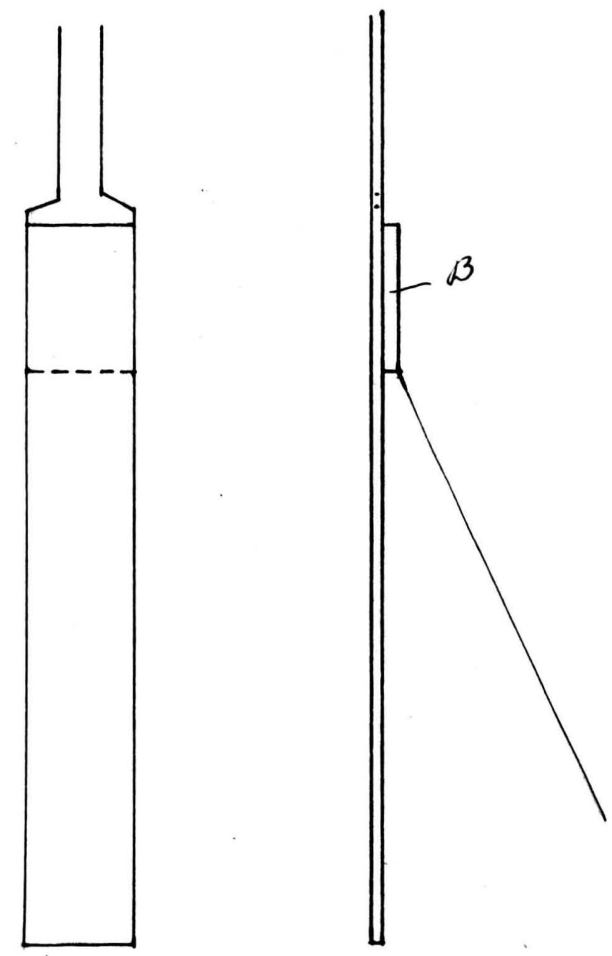

FIs. 11. Detall of Leaf Systems. 

(67)

perfectly air tight joints. In connection with the construction of the electroscopes a method reates

for mounting the glass, was worked out, which yeilded satisfactory results. The surface of the metal and of the glass was first thoroughly cleaned. The picein was warmed just enough to make it soft and easy to work into shape with a knife or spatula. The wax was now pressed tightly into the grove on the edges of the frane and finally struck off eren with the edges of the grove with a knife. Care should be ex: ercised to get the plate glass cut so as to it the frame closely, or the picein will not be able to hold a racum th warm rooms, or in hot weather. Both the glasses were now placed on the bed of picein and the whole firmly pressed together. The frame with the glasses in position was placed front down on top of a steam oren, or over a radiator, and weighted to press the plates home. The frame was left on the radiator until the wax had softened thoroughly, and the plates had sunk 

(68)

as closely together as possible. The frame was now transfered to a table front down, and the weights replaced. The whole was allowed to stand in this position for three or four hours. In this way the wax fills all the space between the glass and frame with a thin film of wax which adheres very firmly. After this method of mounting was followed no trouble was exgerienced with leaks around the glass plates, or with the pulling out of the wax.

The frame was provided with two good brass stop cocks as shown. These were found to be perfectly tight when they were lubrieated With a stiff rubber lubricator such as is used for racumn desticators. After the stop cock was opened or closed the conical plus was pushed inwards.

The frame contained an opening about 2.5 centimeters in diameter near the middle of the top. This opening had a shoulder (s) which served to support the glass tube (T) about 

(69)

2.5 centimeters in diameter and about eight centimeters long. The glass tubing was surmounted by a threaded brass ring, $(R)$ into which the removeable brass cap screwed. The glass tube was joined to the frame and ring (R) by means of picein wax. The wax was first placed on the shoulder and then the heated glass tube pressed dow until the wax had become hard and solid. One of the objectionalle features of this form of electroseope was this glass tube and cap. It has a slight tendency to change its position, due to the softening of the wax when placed in a warm room or near a radiator.

A small peice of glass tubing four millimeters in diameter passed through a hole in the brass cap (c). The tube was secured in place by means of wax. A brass rod was cemente ifside the small glass tube by means of suiphur. The lower end of the brass rod was imbedded in a rod of sulphur (I) fire millimeters in diameter and six centimeters long, which served as the insulator for the leaf 

(70)

system. At the lower end of the sulphur rod was mounted the brass plate to which the aluminum leaf was fastened. A thin piece of brass (B) (Fig. 1I) was soldered to the upper end of the brass plate, in order to give a straight line of attatchment for the leaf - The leaf of aluminium about ten millimeters wide and sixty millimeters wide was fastened to the piece of brass (B) by means of a,little turpen-. tine which had been exposed to the air.

A special feature of the Boltwood electroscope is the method of charging it. A small peice of soft iron wire (W) (Fig. 9) was suspended from a hook on the brass rod (M) which projects out through the cap. The wire extendsajust below the sulphur insulation and terminated in a loop. In its nornal position the wire did not touch the blade, but it equld be deflected by means of a magnet so as to make contact with the leaf system,for charging by bringing the strong magnet near it, or the contact could be made by tipping the 

electroscope slightly. This device per-

mitted the electroscope to be charged without opening it.

All the brass joints of the electroscope vere soldered except the joint between the brass ring $(R)$ and the remorable cap and this was closed by means of a rubber washer. The case of the electroscope was tested and found air tight. The volume was five hundred anci ninty cubic centimeters.

The frame was securely mounted on a heary wooden base as shown in figure 10 by means of four bolts. This base also supported the cradle for the reading microscope by means of which the position of the leaf was ascertained. The reading microscope consisted of a Ross one and one half inch objective, and a Owo inch eyepiece mounted in an ordinary draw tube. The eyepeice contained a scale which was divided into one hundred divisions. Since only two readin nicroscopes were available for four electroscopes a smallcrade (Fig. 12) 

(72)
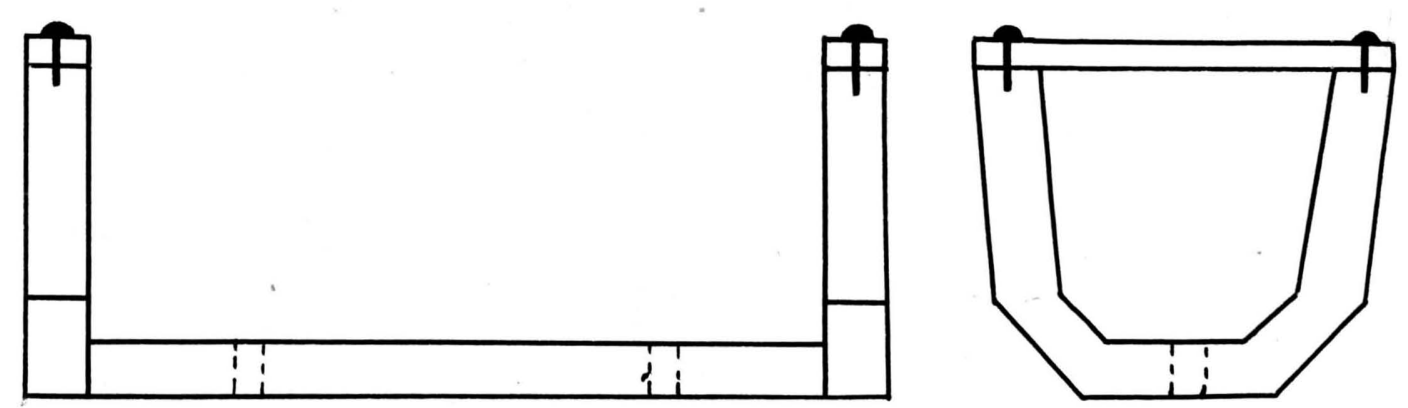

Fig. 12. Cradle for Readin Mieroscope. 

(73)

was designed, and constructed from brass by the university mechanician. The cradle was fastened to the wooden base of the electroscope by means of two screws. The method of mounting the microscope in the cradle is shown in figures 10 and 14. By using this device the reading microscope could be remored and replaced in the same position.

\section{Hlectroscope Nimber 4. Hlectroscope}

number 4 was of a design which has not, to my knowlege been described in the literature. It was constructed by Prof. Herman Schlundt and consisted of a rectangular hrass frame with plate glass front and back (Fig. 14) similar to the Boltwood form. The frame was prorided with two large brass ctop cocks made by A. Pfeiffer, Wetalar. Instead of a shoulder for holding a glass tube, the frame was provided with a threaded brass ring(R). The leaf syst consisted of a brass plate, with the aluminium leaf mounted as in figure 11, attatched to a copper rod. The upper end was fastened into 

(74)

Fig. 13. Electroseope No. 5.

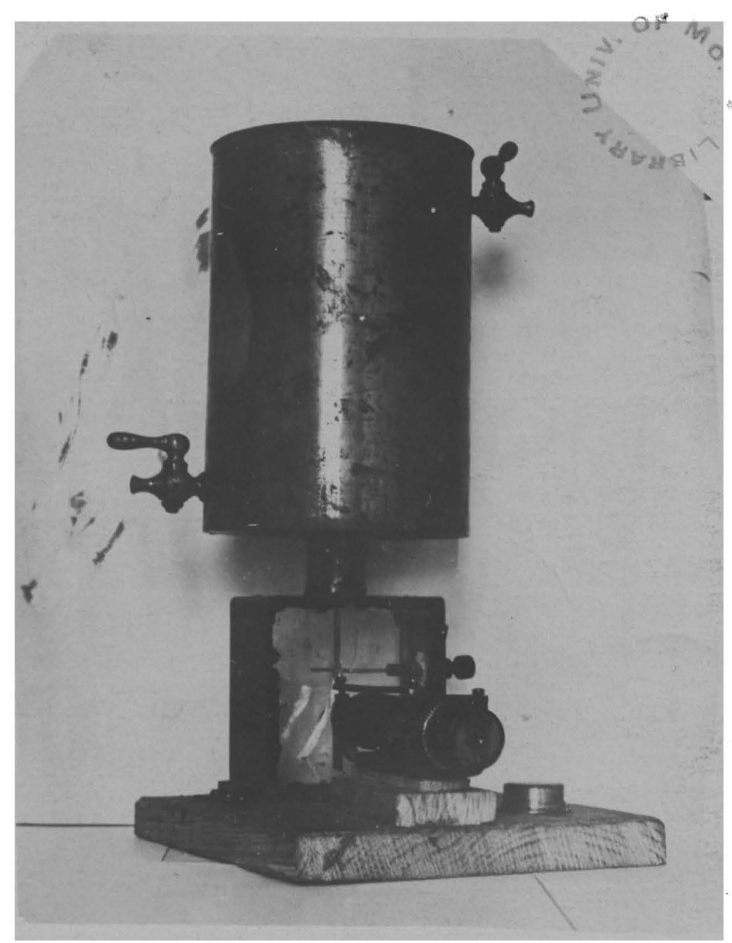

Fig. 14. Electroscope No. 4.

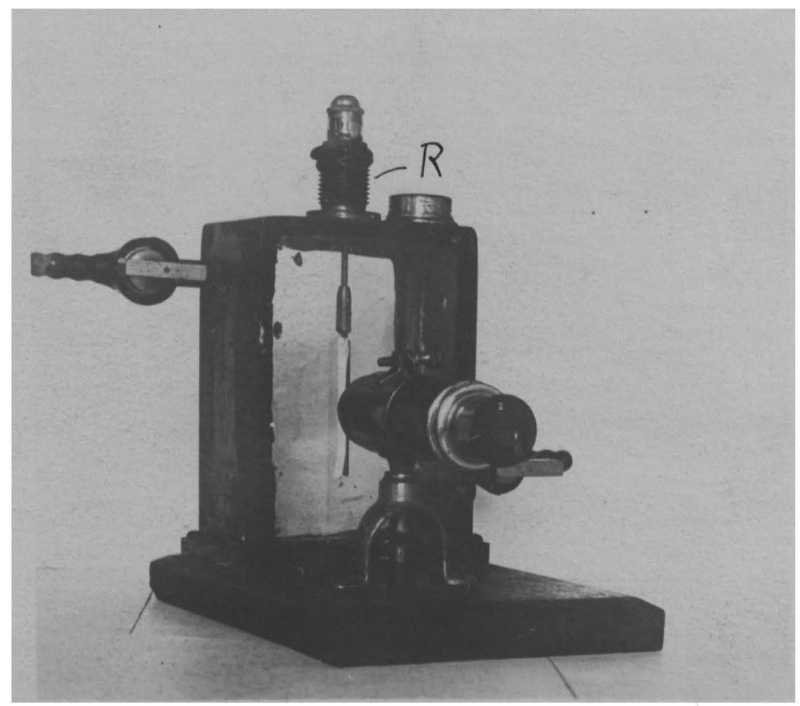





\section{(75)}

a hollow brass cylinder, threaded so as to fit the brass ring (R) by means of sulphur which served as the insulator. A small brass cap for the protection of the insulation was fitted over the projecting end of the brass rod of the leaf system. The electroscope was charged by ouching, the leaf system, the case being earthed. This electroscope had a rolume calculated from the internal dimensions of the case of 955 cubic centimeters, by actual measurment of 952 cubic centimeters.

The electroscope was provided with a reading microscope, a Bausch and Lomb combination of a thirty two millimeter objective and two inch eyepiece mounted in a draw tube. The microscope was mounted in a collar saldered to a circular rod, held in position by means of a set screw. This form of mounting did not possesspthe rigidity shown by the cradle mounting, with which the other insturments were provided. Moreover, in case the microscope was disturbed, the insturment had to be restandardized. 



\section{(76)}

This electroscope was first called number $4 a$ when the glass front cracked. After the replacement of the front the electroscope wa called number $4 \mathrm{~b}$, then the position of the reading microscope was altered somevhat, space for keeping the electroseupe meer lock and key not being arailable. A new leaf was also mounted at this time and the instrument called number 4c. After each of these changed the scale of the reading microscope was recalibrated.

Flectrascope Number 5. Flectroscope number 5 was constructed after the design of Schmidt(1). It consisted of a cylindrical brass vessel fitted with two stop cocks. The top of the ressel could be removed, and the bottom carried a threaded brass ring through which the electrode of the leaf system projected, and by means of which it could be attatched to the frame of the electroscope with a rubber washer. The leaf system consisted of a brass plate, carrying the aluminium leaf mounted as before, at tached to a brass rod. The rod of the leaf system passed through a sulphur plug in the

(1) Sehmidt, H. .,, Physik. Z. 6, 551, 1905. 

(77)

top of the frame, and ca ried on its upper end a central electrode one centimeter in diameter and fifteen centimeters in length. The frame was fastened to a wooden base (Fig. 13) which carried the cradle for the reading microscope, which was the same as was used on electroscope number 2. In order to obtain greater sensitiveness the microscope vas mounted so as to read the edge of the lower part of the leaf, which was approximately the same size as that of electroscope $n$ number two. While this was the position of $t$ the reading microscope when the electroscope was used in the regul $r$ experiments, it was found nefcessary when the electrostatic capacity was to be determined, to mount the cradle temporarily so that the microscope would read the edge of the upper part of the leas. Considerable difficulty was experienced in getting th ionization chamber air tight due to defective stop cocks, so that the values for current given in the tables below may be somewhat low. This insturment showed the "crawl effect" to be described later to a marked degree. The leaf was also disturbed by 

air currents and outside electricel disturbiancestrich made the measurments with this inst urrent 1 more or less unsatisfactory. The dats obtained are added for completness and for thier qualitative value.only.

Flectroscope Number 8. This insturment of the same general design as number 4 but with a smaller ionization chamber, was the most reliable electroscope used. The same frame as was used for electroscope number two was used. The glass tube and leaf system were removed and replaced by a simplified leaf system similar to that of number four. The leaf was supported by a very narrow strip about one milimeter wide. With these exceptions the insturment vas exactly the same as electroscope number two.

\section{Determinati on of, the filectro-} static Capacity of the Electroscopes.

The Standard Copucity. For determining the capacity of the electroscopes a callorated ain Harmp $\mathrm{s}_{\Lambda}$ condenser was used. The condenser as as sembled is shown in rigure 15. The parts are 

(79)

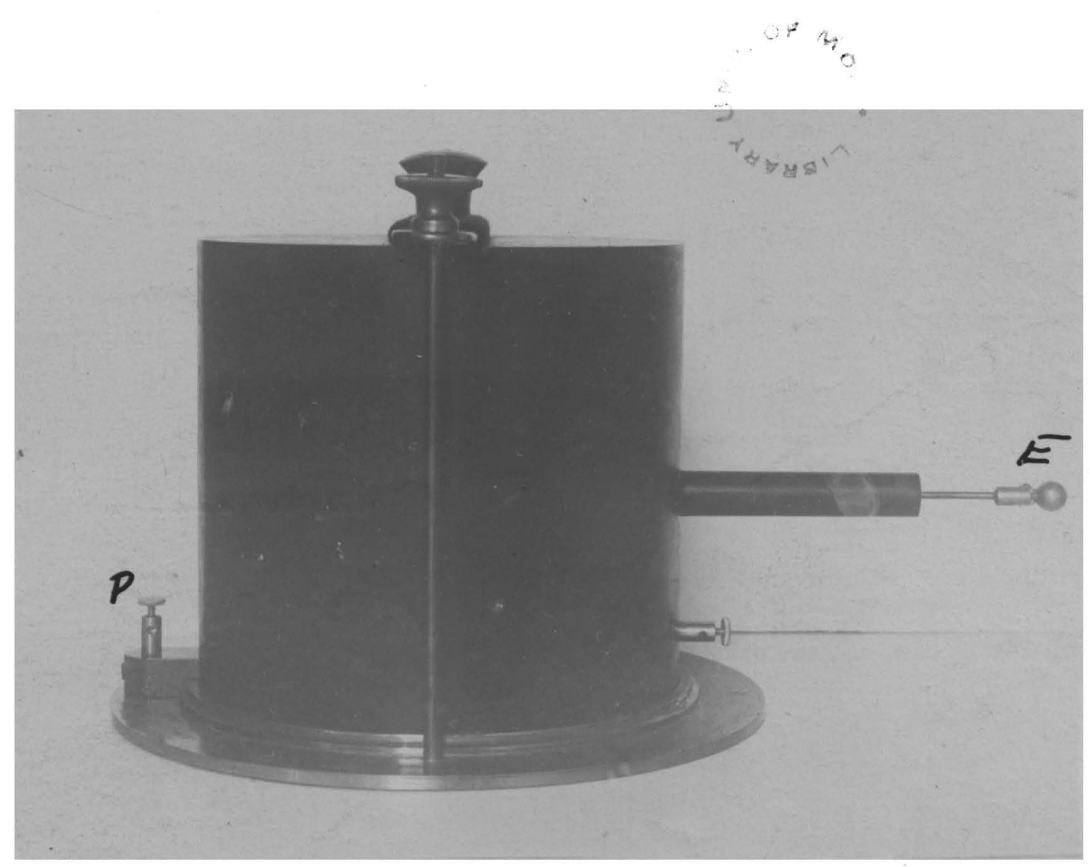

Fif. 15. Harms Air Condenser.

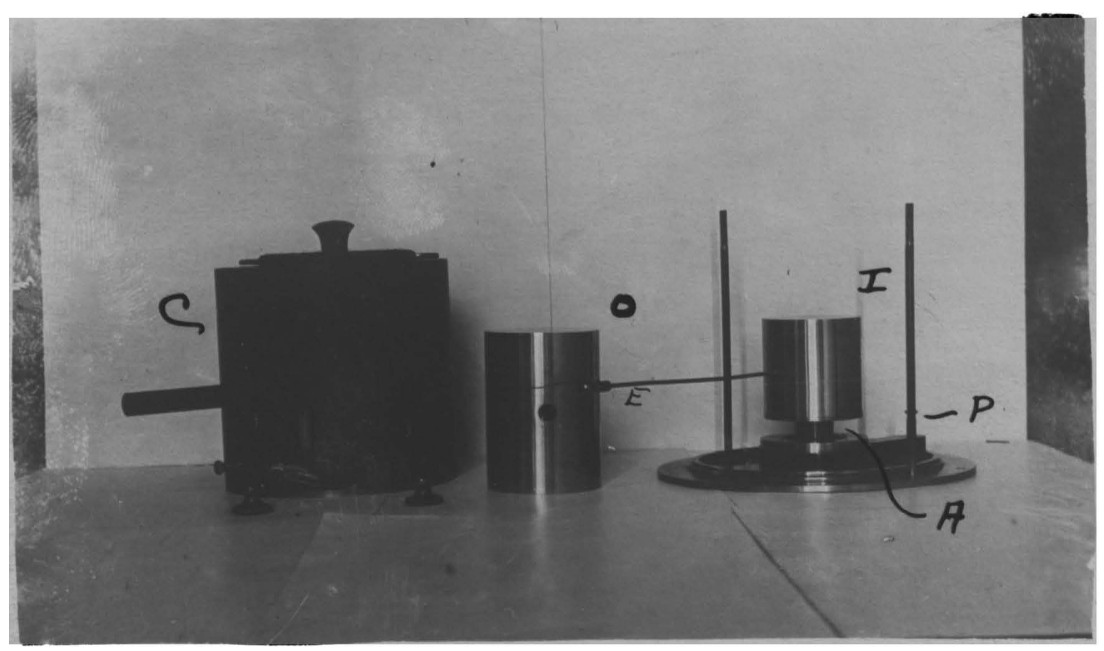

Fig. 16. Parts of the Condenser. 

(80)

shown in figure 16. The Harmps condenser (1) consists of an inner cylinder (I) supported upon an amber block(A). The inner eylinder is surrounded by an outer eylinder (0) insulated by vuleanite and connected to the binding post (P). The inner cylinder is provided with an electrode (B). The vihole is enclosed in a metal case (C) which is kept grounded in order to avoid outside electrical disturbances.

Source of Potential. As a souree of potential, storage cells and dry batteries were used. The storage batteries vere mounted in the case shown in figure(I7) The set consisted of ninty nine eells connected in seriespo as to furnish approximatly two hundred rolts. Two four candle power lamps were placed in series

$$
\text { (I) Harms, F., Physik. Z, , 5, 47, } 1904 .
$$

Insturment Ho. 2240 furnished by Gibther and Tegetmejur of Braunschweig. Capacity charged by inductivis 42.5 cendusineters. 

(81)

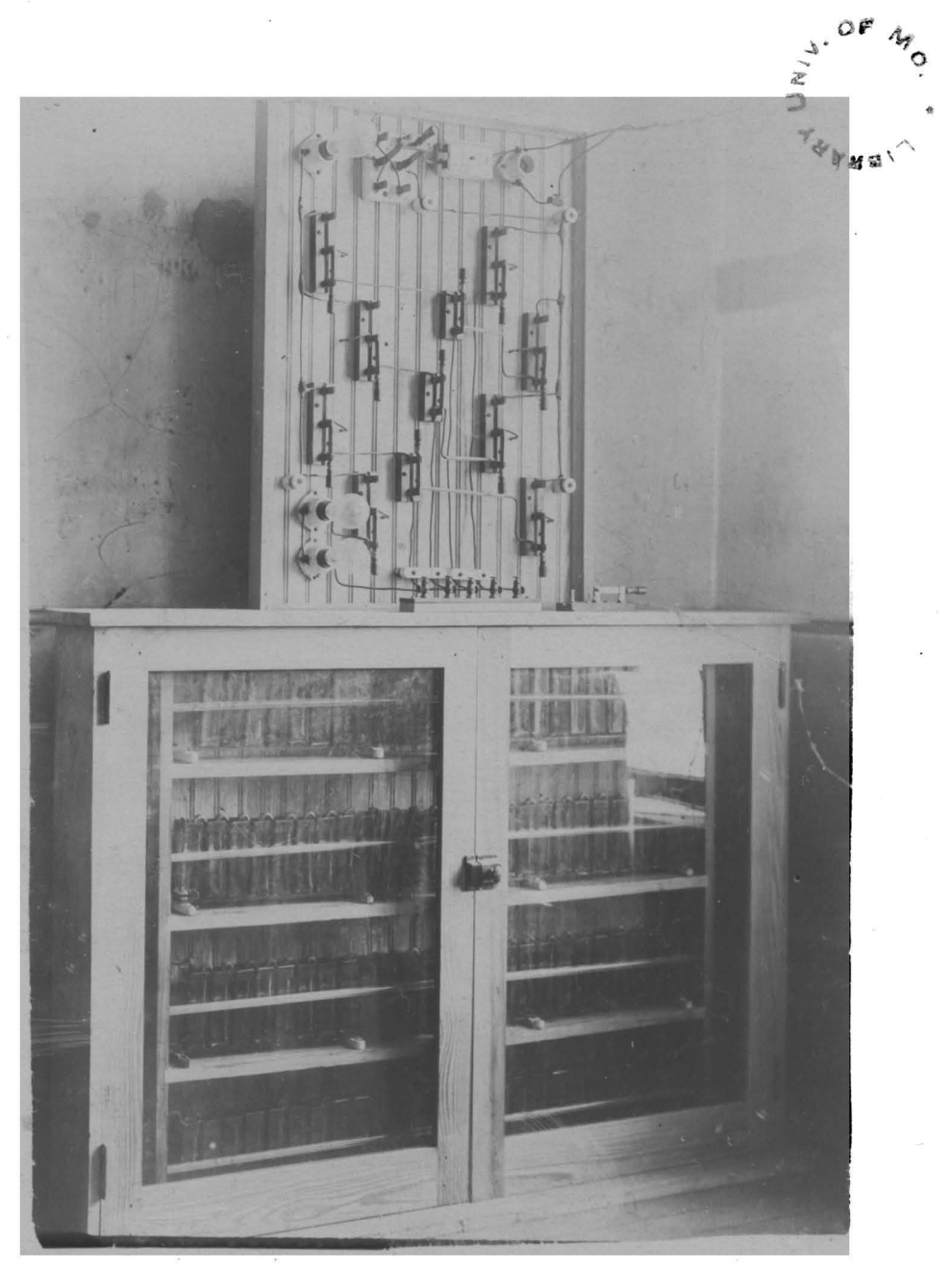

F1E. 17. Storage Batteries.

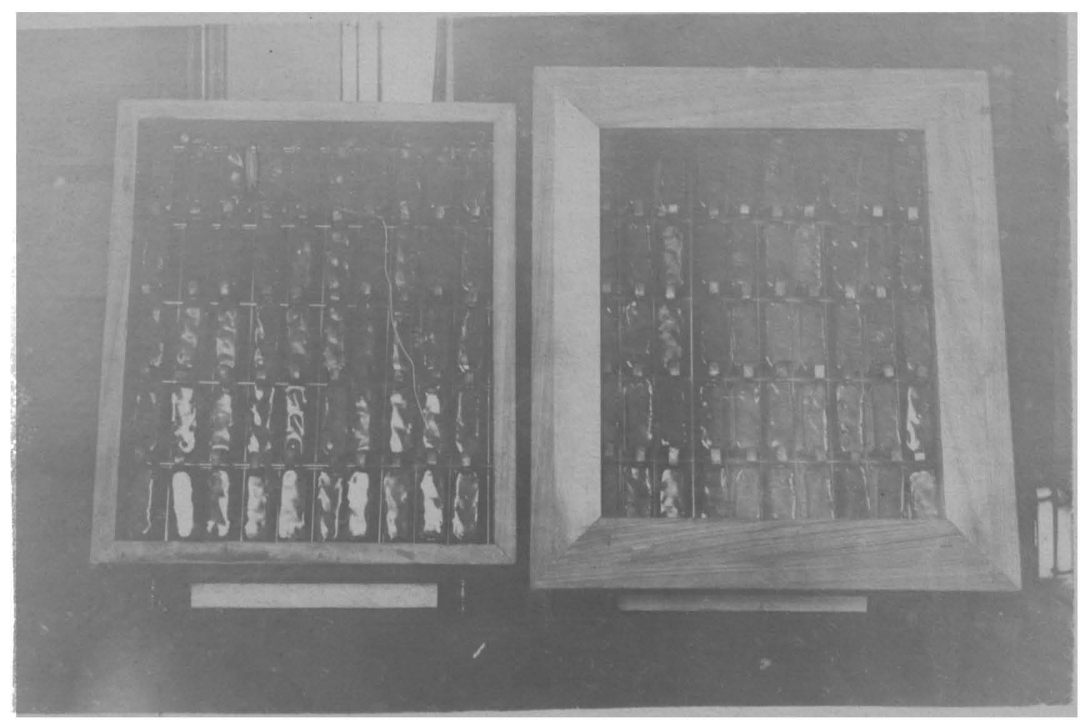

Fig. 18. Dry Batteries. 

(82)

to avoid acidental short circut of the storage cells.

It was found necessary to carry out these experiments with potenitals over two hundred volts so dry eells were added. One hundred flash light batteries (1) were connected in series and mounted as shown in figure 18. Fifty sets were placed in each box and insulated by means of a glass plate in the bottompand glass rods between the rows. These dry batteries furnished an additional potential of about four hundred volts, so that in all about six hundred volts were available. Determination of the Potential of the Battery and Calibration of the scales of the Flectroscopes. For determining the potential of the charging batteries a voltmeter with a scale reading from zero to three hundred

(1) Columbia Flash Light Batteries No. Ov3, made by National Carbon Co., Cleveland, a. 10. 



\section{(83)}

volts (1) was used.This voltmeter was compared with a the standard Weston roltmeter of the Fngineering Department, and found correct to 0.2 volt for potentials between zero and one hundred and fifty volts.

Two diffieulties presented themselves. First the potentials used were greater than could be registered on the voltneter, and second the resistence of the batteries was great enough, that the current used bj. the roltmeter caused an appreciable drop of the potential.

In otder to overcome the firat diffieulty the battery was divided into three sections, the storage batteries (SB), and dry battery sets ( $D B I)$ and (DB 2). The elcetrotuen motive force of each section was determined separately.

(1) Voltmeter No. 74504. American Insturment Co., Type 4., scales 0-3, 0-15, and 0-300. Resistance of voltmeter 0-300 scale was ahout 30000 ohms. 

(84)

since the detemination of the electronotive force of the batteries also involved the calibration of the scales of the electroscopes these two operations will be described as one. The elcetroscopes were leveled by means of a small circular level placed on the case. (Fig. 13). The negative pole of the storage batteries (SB) was placed in contact with thepeaf system of the electroscope. In th case of electroscopes numbers four and eight the contact was made with the projecting rod of the leaf system. In the case of electroscopes numbers two and fire the glass back of the frara was temporatily replaced by a flass plate having a small hole seven railimeters in diameter opposite the blade of the leaf system. The positive pole of the storage batteries was con-. nected to the negatire of (DB 1 ), and the positire of (DBI) to the necative of ( $\mathrm{DB} 2$ ). The case of the electroscope was earthed, and to the earth connection was attatched a traveling electrode, which could be attat/ched to any of the. 

(85)

several points where the dry batteries were soldered together.

The next step was to find the approximate value of one scale division in volts. The negative terminal of the voltmeter was attatched to the negative terminal of (DB 2) and the positive terminal to the traveling electrode. The traveling electrode was now attatehed to thesereral points of the battery in sucession. The voltmeter reading and the position of the edge of thelpeaf on the scale were noted for each point. From thesedata the approximate value of one scale division in rolts was calculated.

The position of the leaf with the voltmeter in and out of cireut was now noted for the several points. From the difference of the scale readingswith the voltmeter in and out of circut the drop of potential due to the current taken by the voltmeter was calculated, and then added to the voltage observed when the voltmeter was in circuxt for that point. This 

(86)

pre the electromotive of that portion of

(DB 2) which was used.

The negative terminal of the roltmeter was now transfered to the negative terminal of (DB 1 ) and the positive terminal to the positive terminal of (DB 1$)$, and the difference on seale reading with the roltmeter in and out of circut determined. The value of one scale division had already been found so the ${ }_{\Lambda}$ drop was calculated and added to the observed voltmeter reading. The electromotive force of the storage batteries was determined in the ame way. The method of ealeulation will ap ear elear from the data given in tale $I$, which is a specimen set of data. 

$(87)$

Table I. Data for Calibration of the Scale of Electroscope Number 2.

\begin{tabular}{|c|c|c|c|c|c|c|c|c|c|c|c|}
\hline & $\begin{array}{l}\text { V. } \\
1\end{array}$ & 2 & $\begin{array}{r}\mathrm{s}_{1} \\
3\end{array}$ & 4 & 5 & $\begin{array}{l}\mathbf{s}_{2} \\
6\end{array}$ & 7 & 8 & 9 & $\begin{array}{l}E_{1} \\
10\end{array}$ & $\begin{array}{l}\mathrm{B}_{2} \\
11\end{array}$ \\
\hline A & 170 & & 84.0 & & & 93.0 & 9.0 & 9.3 & $179.3^{-}$ & 365.8 & 375.1 \\
\hline b & 154 & 16 & 68.5 & 15.5 & 1.03 & 77.0 & 8.5 & 8.8 & 162.8 & 349.8 & 358.6 \\
\hline 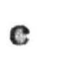 & 142 & 28 & 57.5 & 26.5 & 1.05 & 64.5 & 7.0 & 7.2 & 149.2 & 337.8 & 358.6 \\
\hline d. & 126 & 44 & 41.5 & 42.5 & 1.03 & 48.0 & 5,65 & 5.7 & 131.7 & 321.8 & 327.5 \\
\hline$e$ & 114 & 56 & 29.0 & 55.0 & 1.02 & 35.0 & 6.0 & 6.2 & 120.2 & 309.8 & 316.0 \\
\hline$f$ & 101 & 69 & 18.5 & 66.5 & 1.04 & 23.0 & 4.5 & 4.6 & 105.6 & 296.8 & 301.4 \\
\hline ⿷匚 & 87 & 83 & 4.0 & 80.0 & 1.04 & 7.0 & 3.0 & 3.1 & 90.1 & 282.8 & 285.9 \\
\hline$f$ & 103 & 69 & 19.0 & 67.0 & 1.03 & 23.0 & 4.0 & 4.1 & 107.1 & 298.8 & 302.9 \\
\hline d & 124 & 56 & 40.0 & 56.0 & 1.00 & 45.0 & 5.0 & 5.2 & 129.2 & 319.8 & 325.0 \\
\hline c & 144 & 28 & 59.5 & 26.5 & 1.05 & 65.0 & 5.5 & 5.7 & 149.7 & 339.8 & 345.5 \\
\hline W & 164 & 16 & 78.0 & 16.0 & 1.00 & 83.0 & 5.0 & 5.2 & 169.2 & 359.8 & 365.0 \\
\hline & 172 & & 86.0 & & & 92.5 & 6.5 & 6.7 & 178.7 & 367.8 & 374.5 \\
\hline & 185 & & 82.0 & & & 92.5 & 10.5 & 10.8 & 195.8 & & \\
\hline
\end{tabular}

(DB 2) was not used. The points $a, b$, ete. were taken from ( $D B$ 1). 

(88)

Column (1) of the table gives the roltage as read off the voltmeter. Column (2) gives the bation from paint a, increment in $\mathrm{V}$, column 1 . Column 3 gives the scale reading $s_{1}$ correspoding to $v$. Column (4) refued ct rimeicas raene of $s$, gives the increment of $\mathbf{s}_{1} ;$ Column (5) gives the value of one scale dieision as calculated from colurans (2) and (4). Column (6) gives the scale reading with the voltmeter out of circut corresponding to $\mathrm{SI}$. Column (7) gives the difference $\mathbf{s}_{2}-\mathbf{s}_{\mathbf{1}} \cdot \quad$ Column (8) gives this difference reduced to volts by multiplying by the mean of Column (5). Column (9) gives the electronotive force of the scetion of the battery measured by the voltmeter. Column (10) gives the total eleetromotive force corresponding to $\mathbf{s}_{1}$. Column (11) gives the electromotive force corresponding to

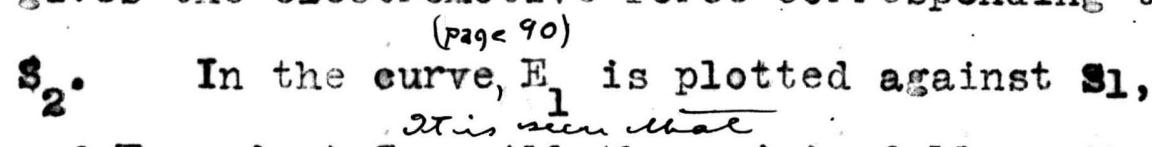
and $\mathbb{E}_{2}$ a ainst $\mathbf{s}_{2}$. dil the points fall on the same straight line.

Later in theinvestigation one of the electroscopes was used as an electrostatie 

(89)

voltmeter for determining the electromotive force of the battery. The results of the calibrations of the electroscopes are shown on curve sheets (1) to (7) which are self explanatory. The dry batteries were found to give satisfactory results for thins work if care was used not to leare the voltmeter in circut for more than two minute inturals.

$$
\text { Schmidt (1) has pointed out that the }
$$
potential registered by an electroscope was not proportional to the scale divisions. This conclusion has been verified in the case of electroscope number four. With three different aluniniun leaves it gave calibration curves which were not straight lines, see curre sheets 2), (3), and (4). It will be noted that the calibration curves obtained with electroscopes numbers two, fire and eight were straight line auryes, or that the potential, between the limits

(1) Schraidt, H. W., Physik. Z., 7, 157, 1905. 



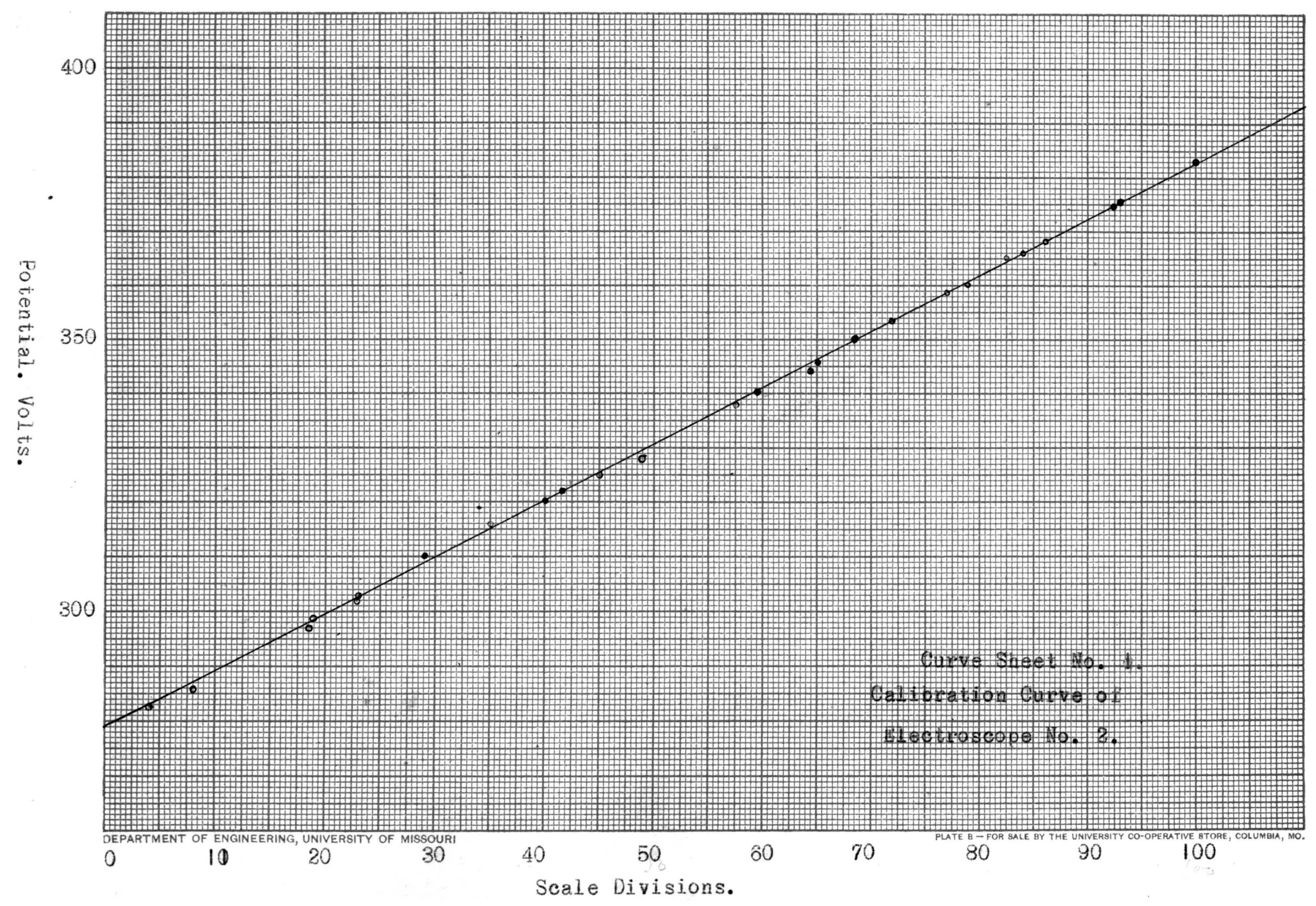





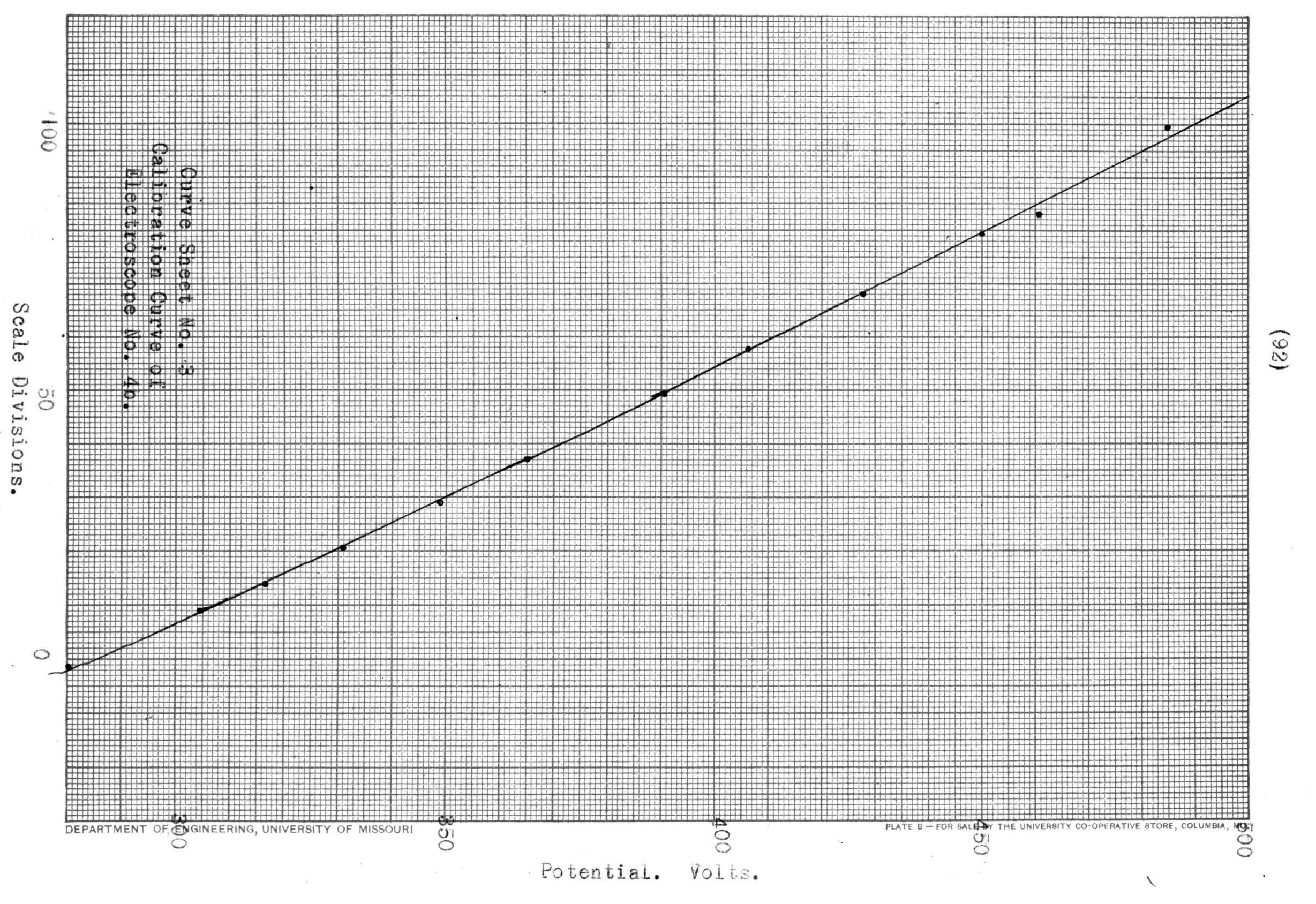





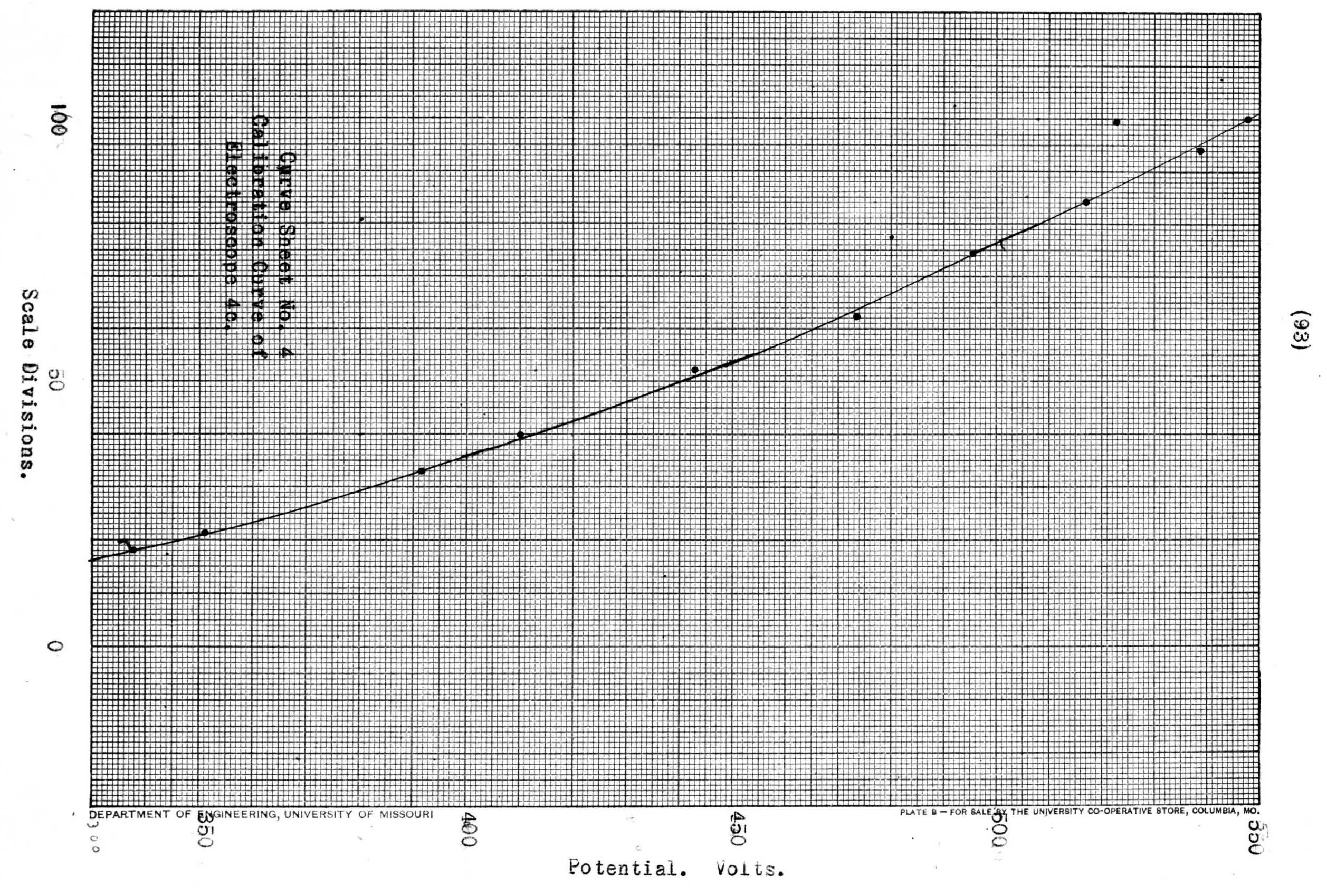





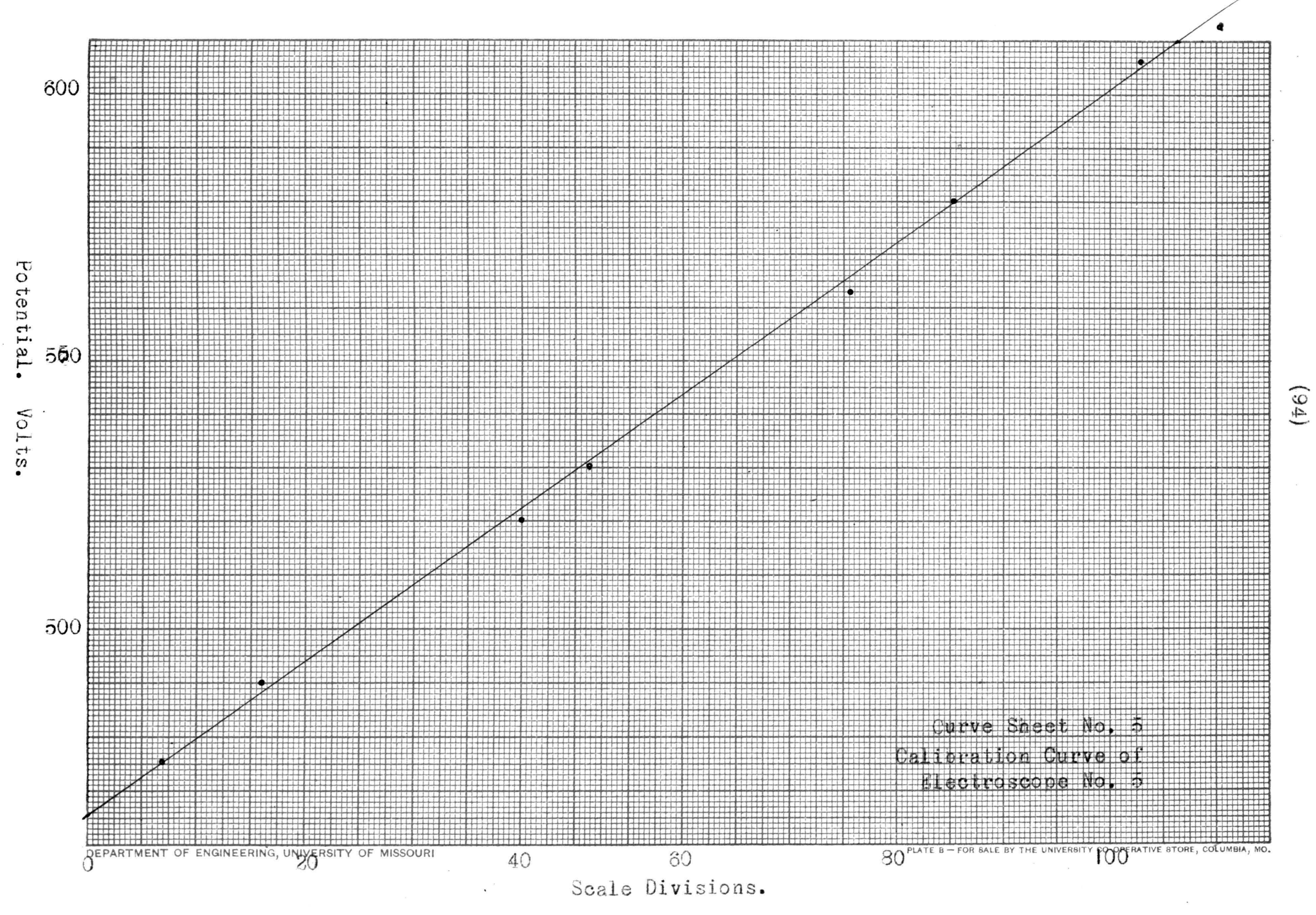





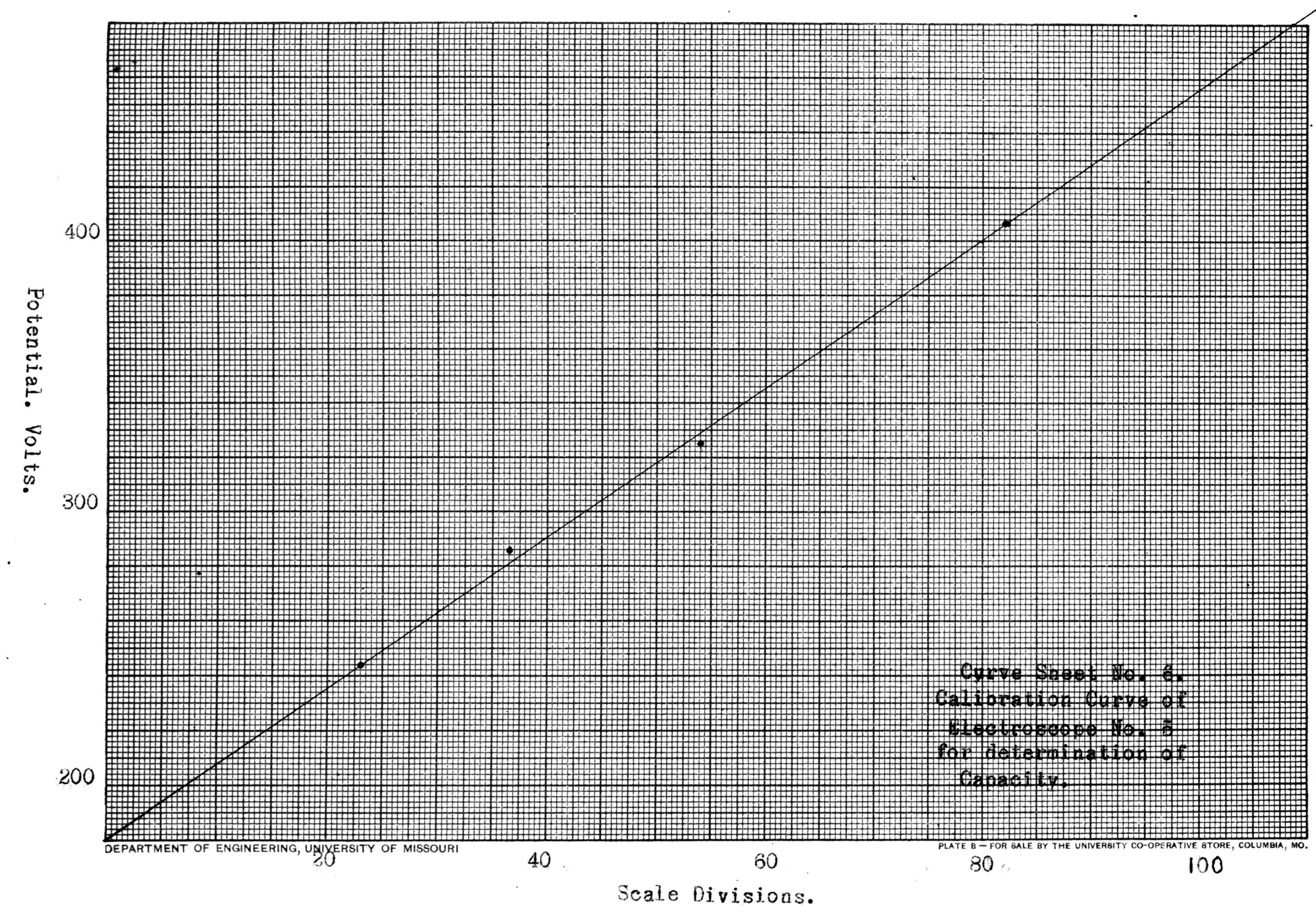





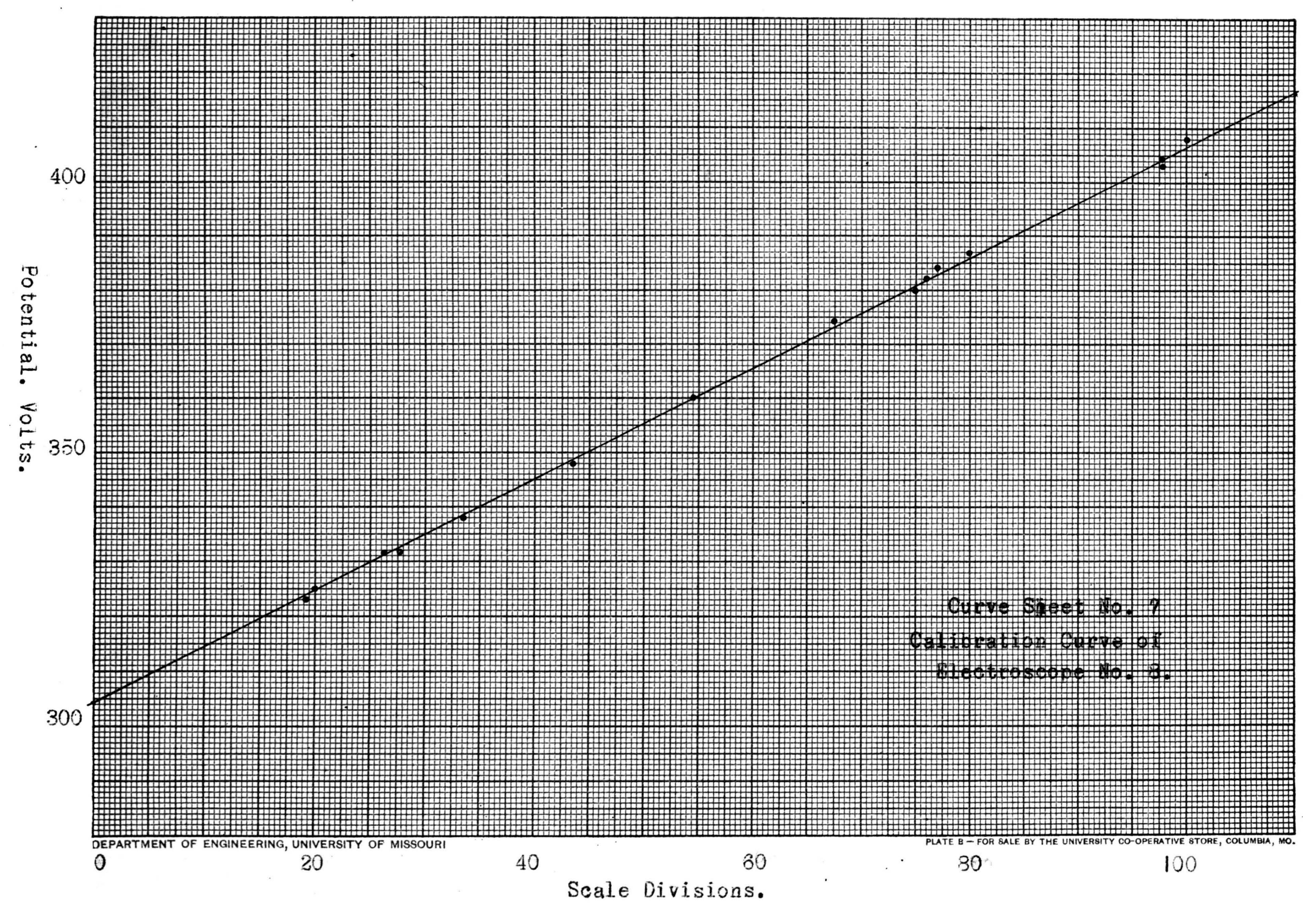



of calibration vere proportional to the scale reading. See curre sheets (1), (5), (6), and (7). The specific factors which ef fect the form of the calibration curve obtained from different ele ctroscopes have not been ascertaified, however it appears that the form of curve obtained will depend upon the form, size, and shape of the individual electroscopes as well as upon the properties of the leaf itself'.

The 功ectrostatic Capacity of the

Hilectroscopes. For finding the electrostatic capacity of the clectroscopes the method of Harms (1) was used. The joint capacity of the leaf system and the condenser was first determ ined as deseribed by Harmps:-

The case of the electroscope was earthed, and the negative pole of the battery, arranged as before, placed in contact with the leaf system as described for ealibrating the scale. The movable electrode was attatched to the battery

(1) Harms, F. Boc. Cit. 

(98)

so that the leaf would be near the upper end of the scale. The position of the leaf $\left(s_{1}\right)$, was read on the scale and the voltage of the battery $\left(\nabla_{1}\right)$ determined by reference to the. curve sheet for the particular electroscope. The outer protecting case of the condenser and the leaf system of the electroscope were then earthed. The outer eylinder of the condenser was then charged by means of thepattery whose eletromotive force had just been determined as above. The inner eylinder of the condenser was earthed. After at least two ninutes the earth connectionswith the leaf system of the electroscope, and with the inner cylinder of the condenser were broken. The connection between the battery and thelouter cylinder of the condenser was then broken, and the outer eylinder earthed. In this way the condenser was charged by induction.

The electrode of the inner cylinder was now touched to the leaf system of the electror 

(99)

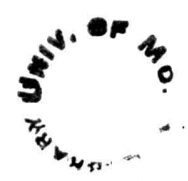

scope, and the position of the leaf $\left(\mathrm{s}_{2}\right)$ noted. The potential $\left(v_{2}\right)$ was determined by refer ence to the curve.

The joint eapacity,

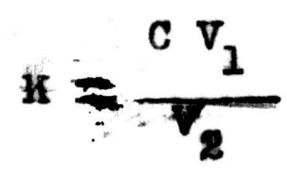

itm whe (C) is the capacity of the condenser or 42.5 centimeters, and $(K)$ the joint capacity. The next step was the determination of the electrostatic capacity of the elcetroscope, which vas carried out as follows:-

The inner cylinder of the condenser was placed in contact with the leaf system of the electroscope; the outer cylinder and case of the condenser, and the case of tho electroseope were earthed. The condenser was now charged so thet the leaf cane on the upper part of the scalepf the reading nicroscope. The position of the leaf

(1) $\mathrm{K}$ is naturally not the sum of the capacity of the condenser and electroscope, as was pointed out by Harraps. 

(100)

$\left(\mathbf{s}_{11}\right)$ was noted. The contact with the leaf systen was broken and the condenser removed several feet from the electroscope. The position of the leaf $\left(\mathrm{s}_{12}\right)$ was noted and the leaf earthed for at least two minutes. The electrode of the inner cylinder was again brought in contact with the leaf system and the reading $\left(\mathbf{s}_{13}\right)$ noted: The potentials $\left(v_{11}\right),\left(v_{12}\right)$, and $\left(v_{13}\right)$ correspond ing to the scale readings $\left(s_{11}\right),\left(s_{12}\right)$ and $\left(s_{13}\right)$ were obtained by reference to the curve for the particular insturment used. The capacity of th elechorerpe,

$$
c=\frac{k\left(v_{11}-v_{13}\right)}{v_{12}} \text {. }
$$

An example:-

The condenser was charged by induction to a potential of 593 volts. This charge, divided between the leaf system of electroscope number fourgave a reading on the scale of $0.0 \times 416$ rolts. From thesedata the joint capacity $(K)$ is 60.6 centimeters.

The condenser and leaf ystern were charged to a potential $\left(\$_{11}\right)$ scale reading.0. On removing the condenger $\left(s_{22}\right)$ was 91.0. , The leat 



\section{(101)}

was earthed for two minutes, insulated, and the charge on the condenser divided. The reading $\left(S_{13}\right)$ was 33.2. The voltages $\left.\left(v_{11}\right), t_{12}\right)$, an $d\left(v_{13}\right)$ vere 588.4, 583, and 485.3 respectuly. From thesedata the cepacity of electroscope nuber four without cap vas 10.7 .centimeters.

Some of the determinations in ber four electroscope were made with the cap in place. The reading $\left(\mathbf{s}_{21}\right)$ was made with the electroscope charge without cap. The cap wa now fitted in place and the reading $\left(\mathbf{s}_{\mathbf{2 2}}\right)$ taken. A determination gave $\left(\mathbf{s}_{\tilde{Z}^{1}}\right)$ as 97.0 an $\left(\mathbf{s}_{22}\right)$ as 82.7. $\left(v_{21}\right)$ and $\left(v_{22}\right)$ were 593 and 571 volts. The capacity of the electroscope with cap

$C_{1}$ is given by the equation,

$$
\mathrm{c}_{1} \mathrm{v}_{22}=\mathrm{C} \mathrm{v}_{21} \text {. }
$$

Pron which $\left(\mathrm{C}_{1}\right)$ is 11.1 centimeters.

The results of the determination of the electrostatic capacity are shown in the tableII. The mean of several deterninations ise given in each case. 

(102)

Table II.

Capacity Joint Capacity of the

Flectroscopes.

\begin{tabular}{|c|c|c|c|}
\hline $\begin{array}{l}\text { No. of } \\
\text { Elect. }\end{array}$ & $\begin{array}{l}\text { Joint Cap. } \\
\text { K. cin. . }\end{array}$ & $\begin{array}{l}\text { Capacity } \\
\text { c. cu. }\end{array}$ & $\begin{array}{l}\text { Capacity wit } \\
\text { Cap. } C_{1} \text { cras. }\end{array}$ \\
\hline 2 & 48.9 & 3.01 & \\
\hline 4 & 60.6 & 10.7 & 11.2 \\
\hline 5 & 74.6 & 14.8 & \\
\hline$\dot{8}$ & 53.4 & 6.13 & \\
\hline
\end{tabular}

A "Crawl" Effect. During the early part of the investigation it was observed that the leaf, after being charged, and the battery left in contact, slowly increaces its apparent potential. It was at first thought that this effect might be due to a change in the potential of the dry batteries used. The voltmeter was then connected across the terminals of the dry bati teries and although the voltage remained constant the effect was still observed on chargin the Later it was found that if the leaf was 



\section{(203)}

discharged and then the condenser, with the inner cylinder chargedwas brought in contacy with the leaf, that the same effect was still observed. The amount of increase was in some cases as muc? as twenty-five volts. The effect vas most marked in electroscope number five, but was also observed in numbers two, eight, and four. The potential finnally, after from two minutes to three hours, rose to a definito maximum for each point of the charging battery. If the electroscope was kept charged for a long time and then only partly discharged the maximum value of the potential ias reached very much quicker.

This "crawl effect" made the determinatof the capacity of the electroscopes very troublesome and uncertain in those electroscopes in which it was observed to the greatest extent, namely numbers two and five. The electrostatic capacitjes of numbers fout and eight were-very much easier to determine, joth on account of the lesser "crawl effect" and on ac count of the fact that the leaves could not be disturbed by air currents. 

(104)

It was thought that the effect obseered might be due to induced charges on the surface of the glass plates forming the front and back of the electroscopes. A copper gause was fitted inside the plates and grounded, but the effect was still observed. No further eximents to determine the cause of the effect were carried out. The effect is probably due to some inherent property of the sulphur insulation used, or to some factor which has not been discorered. The only reference which could be found in the literature which suggested the existance of such an effect as was observed was one by Dike(1). He mentioned that in calibrating hid apparatus for measuring atmospherie electricity (Gerdien electroscope insulated by means of amber) that the waited one minute during the charge of the leaf for all the charges on the insulation to become neutralized, but he made

(1) Dike, P. H., Science, 29, 475, 1909; Am. Jour. Sci., March 1909. 



\section{(205)}

no specific mention of an upward "erawl" of the leaf after charging. I had also observed, before the above paper had appeared, that in order to obtain concordant results in the determination of the electrostatic capacity of the electro-, scopes, it was necesary to leare the leaf system earthed for at least two minutes, when it was discharged.

This anomalous beharior of these electroscopes may have some bearing on theobservation recorded by Schlundt and Moore ${ }^{(1)}$ in one of thier papers. They state that at the maximum actirity of a sample of radium emanation, three hours after its introduction into the electroscope, that the activity of the ample apparently increased during the first fire minutes after the leaf was first charged, and that if the electroscope wore allowed to to stand disgharged one hour and tha observations repeated the same $r$ sul ts

(1) Sehlundt and Moore, Trans. Hlectrocheralcal Soc., 8, 292, 1905. 

(106)

would be obtained. This result was sentatively explained by schlundt and Hoore as protbeb ly due to the concentration of an additional quantity of one of the products of rapid decay of the emanation upon the charged leaf system, thus causing slightly more ionization in the irmediate vicinity of the leaf. This increase in activity was also observed in my experiments, but it may be explained in a somewhat differnt manner. The above mentioned anomalous upward "crawl" of the leaf during the first few minutes after charging, would tend to counteract the fall of the leaf due to the ionization current. Sine it was observed that the leaf reached its maximum in a shorter time, if the electroscope had been charged for a time, the effect of the "erawl" would become less noticeale after two or three readinga had heen taken, and the time to pass a given nurt or of divisions would become shorter.

Stewart has pointed out (I) that when

(1) Stewart, O. M., Phys. Rev., 21, 229, 1905. 

(107)

quadrant electrometers vere used for measuring current, that the needle nust be allowed to swing at least twenty five seconds before readings of the relocity of the needle could be taken. This precaution was taken so that the needle could reach a uniform velocity. In like manner it would appefur from these experiments that on $\boldsymbol{x}$ count of the crawl effects, the leaf of the electroseope must be charged to a sufficiently high pontial to give fror one half to. three minutes before the leaf comes upon the scale of the mieroscope. When this precaution was taken very concordant readings vere obtained.

Another anomaly in the beharior of the electroscopes was obserred to a slight extent with all the insturments, but more especially with numers five and eight. It was noticed that the air leak in these electroseopes, which was rather high, apparently decreaced after the leaf had been charged for some time. Ser eral series of determinations vere then taken of the air leak over periods of ahout seven hours. The results of several such series were always 

(108)

similar in thier general tendeney, hut no relation could be deduced as regards the magnitude of the

change in the natural air leak.

One of the series of observations is

shown on curre sheets eight and nine. Curre $\mathbf{s}$ she et eight shows the tine to fall one seale division of the reading mieroscope plotte d againt. the scale division at which the measurnen $t$ was taken. Curre sheet thine shows the time to fall one division plotted against the tinelafter the beginning of the series. The electroseope had not been used for three days previlous to the measurraents here given, and was free from radiun emanation.

It will be observed that the air leak grows less as the time the electrose ope has been charged increases, and that if the electroscope is left discharged for a short time, the same phenomenon is observed in a less degree. It was thought that these results might be due to dust, but sweeping the electroscope out with dust free air did not have any effect. 

(109)

The effect of this disturbance was just opposite to that of the anomaly described before. In this case the uneertainity of the air leak was overeome dyring the regular experiments by keeping the leaf charged by means of the battery during the interval between the introduction of the emanation and the final measurment. The concordant readingsoof time to fall the usual nurber of divisions, which were usually obtained after some five or tefon minutes were taken as the ineasure of the activity. On account of the lack of time this air leak effect was not further studied. The anomaly still needs further investigation however.

Determination of the Relation between the Boltwood Fmanation Standard and the C. G. S. Electrostatic Standard.

After the introduction of the radium emanation which had been boiled off from the standard samples of uraninite in the rarious forms of apparatus, into the electroseopes the Ionization was allowed to reach a maximum 



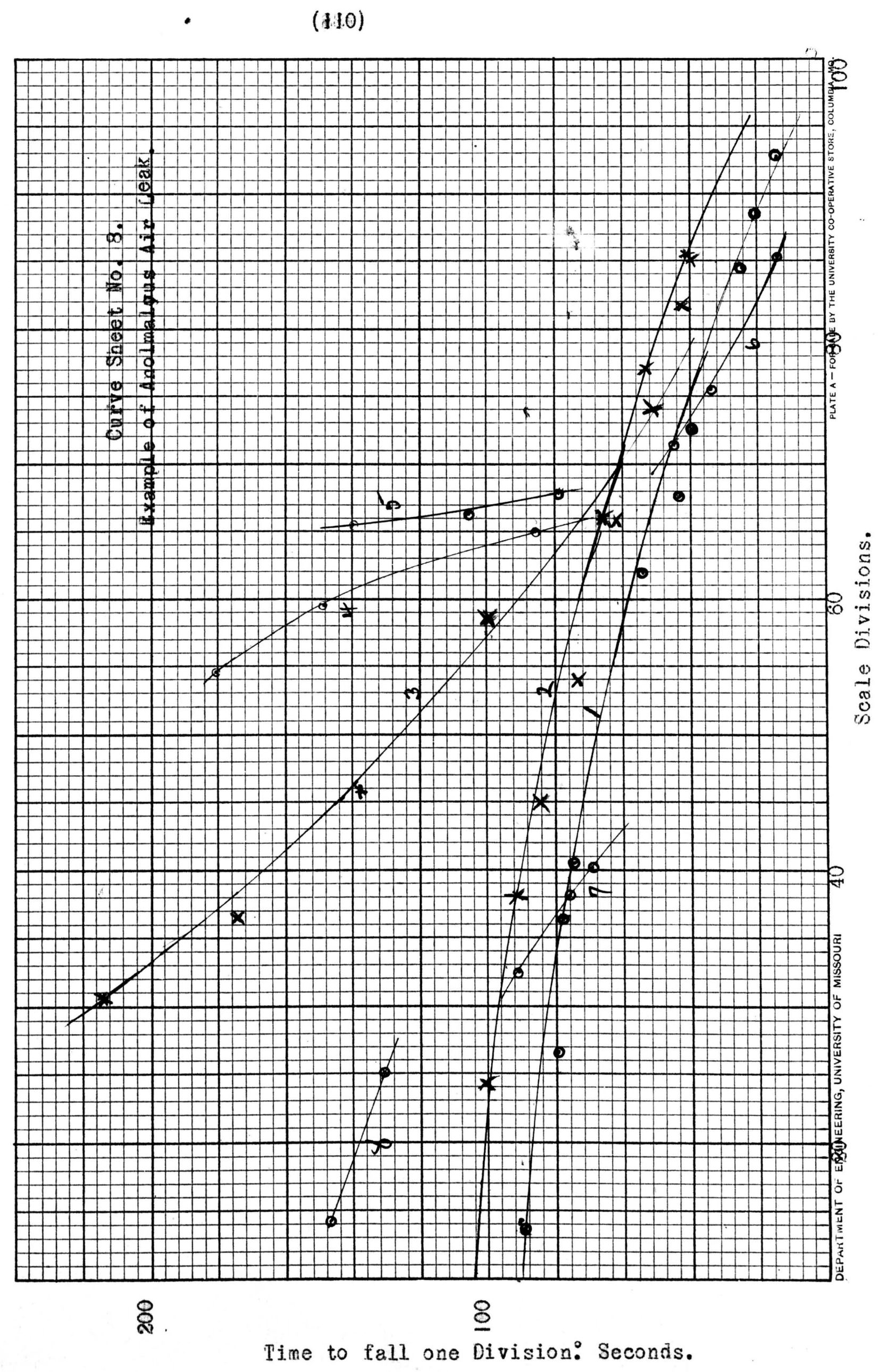





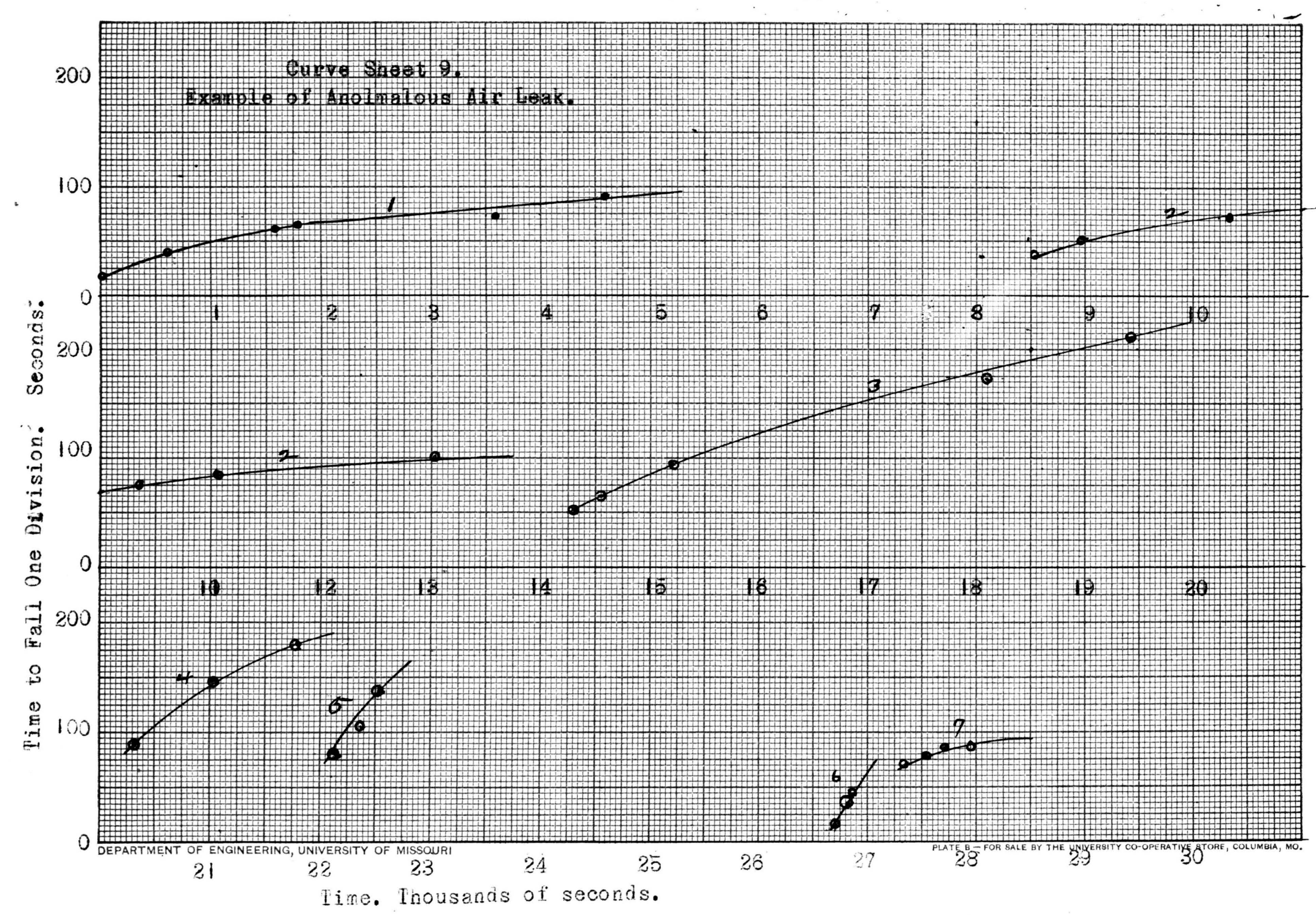



(112)

which required three hours. After this time, the time for the leaf to fall a given number of divisionspin the eyepiece, usually from one hundred to fifty in the ease of electrosagpe number four and from one hundred to twenty in the other instrcments was noted with a stop wateh. From the calibration curre the scale readings were reduced to potential readings, from which the number of volts fall per second was ealculated. From this result was subtracted the number of volts fall of potential per second due to the norraal air leak, determined in each case just before the introduction of the emanation into the electroscope.

The current was then computed from the

following equations:-

$$
i=\frac{c d}{300} \quad \text { c. G. s. . S. U. }
$$

or

$$
i=\frac{C d y}{9 \times 10^{1}} \text { amperes. }
$$

where (C) is the eapacity of the electroseope

(1) Rutherford, F., Radioaetivity. p. 100 . 

(113)

in eleetrostatic units, and (d) the number of volts fall of potential per second, due to the ionization produced by the radiun emanation and its products in equalibrim .

The current produced by the radiwa enictation in equilibrium with one gram of uranium or $3.8 \times 10^{-7}$ gram of radium (1) was found by the equation:-

$$
I=\frac{i}{\text { wt. of U. }}
$$

where (I) is the equlibrium current for the radium emanation from one gram of uranium in a mineral.

The results thus calculated are given in table III columns (5) and (6), Column (1) gives the number of the sample, column (2) the apparatus in which the emanation vas boiled off, coluan (3) the numer of the electroscope used, and column the grams of uranium in the sample. The results of all the determinations are given.

$\therefore \quad$ (1) Rutherford and Boltwood. Am. Jour. Sci., 22, 1, 1906 



\section{(114)}

It will be noted that some of the experiments cre starred (\#), and these, for various: reasons, are not considered as reliable the -thers, as the conditions under which thexperiments were carried out were not idedl (1).

(1) The separation of the radium emanation from the solutions was carried out in the qualitative laboratory, and the electroscopic determinations mede in an upstairs balanee room. At times there was a considerable difference in teraperature in the two rooms, and also at times a large change durin the interval betwe n the in transfer of the gas to the electroscope.

the measurment. Both rooms were open to students, and the locker space for keeping the electroscopes and other apparatus under lock was not available. 

(115)

Table III.

Results of Blectroscopic Deterainations.

1 No. of 2 Appfor 3 I 6 I Sep. No.of Grams Amps. C.G.S. Sample Franation klect. U, $10^{-10^{\circ}}$ R.S.U.

\begin{tabular}{|c|c|c|c|c|c|}
\hline $1 \mathrm{~A}$ & S. \& M. & 4 & 0.01 & 4.10 & 1.23 \\
\hline 21 & S. \& $\mathrm{M}$ & 4 & 0.01 & 4.34 & 1.30 \\
\hline $3 A$ & S. \& $\mathbb{H}$ & 2 & 0.01 & 2.36 & 0.71 \\
\hline $5 \mathrm{E}$ & Strutt & 4 & 0.01 & 3.08 & 0.92 \\
\hline $6 A$ & strutt & 5 & 0.025 & 4.45. & I. 34 \\
\hline $7 \mathrm{~A}$ & strutt & 5 & 0.025 & 4.37 & 1.31 \\
\hline $8 \mathrm{~A}$ & s. \& $M$ & 4 & 0.025 & 4.41 & 1.32 \\
\hline $10 \mathrm{~A}$ & strutt & 4 & 0.035 & $2.98 \#$ & $0.89 \#$ \\
\hline $11 \mathrm{~A}$ & strutt & 2 & 0.035 & 2.11 & 0.63 \\
\hline $12 \mathrm{~A}$ & S. \& $\mathbb{A}$. & 4 & 0.035 & 4.72 & 1.42 \\
\hline $13 \mathrm{~A}$ & S. M. & 4 & 0.05 & 4.80 & 1.44 \\
\hline $15 \mathrm{~A}$ & strutt & 4 & 0.05 & 3.93 & 1.18 \\
\hline $16 \mathrm{~A}$ & S \& M Water & 4 & & & \\
\hline $18 \mathrm{~A}$ & S. \& $\mathbb{M}$ & 8 & 0.1 & 3.01 & 0.90 \\
\hline $19 \mathrm{~A}$ & S. \& M. & 8 & 0.15 & 3.08 & 0.92 \\
\hline $23 c$ & S. \& M. & 2 & 0.01 & $1.71 \#$ & $0.51 \#$ \\
\hline 250 & strutt & 4 & 0.01 & 3.04 & 0.91 \\
\hline
\end{tabular}



(116)

Table III cont.

\begin{tabular}{|c|c|c|c|c|c|}
\hline 1 & 2 & 3 & 4 & 5 & 6 \\
\hline $27 \mathrm{C}$ & s. \& M. & 4 & 0.01 & $1.97 \#$ & $0.59 \#$ \\
\hline $28 \mathrm{C}$ & strutt & - & 0.01 & 2.09 & 0.63 \\
\hline $30 \mathrm{CC}$ & Strutt & 8 & 0.025 & 2.08 & 0.62 \\
\hline $31 \mathrm{c}$ & strutt & 8 & 0.025 & 2.55 & 0.77 \\
\hline $33 \mathrm{C}$ & strutt & 8 & 0.025 & 2.33 & 0,70 \\
\hline $34 \mathrm{C}$ & S. \& M. & 5 & 0.025 & 3.90 & 1.17 \\
\hline $35 \mathrm{C}$ & S. \& $\mathbb{M}$ & 5 & 0.025 & 3.81 & 1.14 \\
\hline $36 \mathrm{C}$ & S. \& $\mathbb{M}$ & 8 & 0.025 & 2.68 & 0.80 \\
\hline $37 \mathrm{C}$ & S. \& in & 8 & 0.05 & 2.92 & 0.88 \\
\hline $38 \mathrm{CC}$ & strutt & 4 & 0.05 & 3.17 & 0.95 \\
\hline $39 \mathrm{C}$ & $S \& M$ Water & 8 & 0.05 & 1.57 & 0.47 \\
\hline $40 \mathrm{C}$ & Strutt & 5 & 0.05 & $2.04 \#$ & $0.61 \#$ \\
\hline $41 \mathrm{C}$ & S. \& M. & 5 & 0.1 & 4.26 & 1.28 \\
\hline $42 \mathrm{C}$ & strutt & 8 & 0.1 & 2.51 & 0.75 \\
\hline $43 \mathrm{C}$ & S. \& $\mathbb{1}$. & 5 & 0.1 & 3.06 & 0.92 \\
\hline $44 \mathrm{C}$ & s. \& $\mathbb{M}$ & 4 & 0.01 & $3.18 \#$ & $0.94 \#$ \\
\hline $45 \mathrm{C}$ & Strutt & 8 & 0.025 & $2 \cdot 28$ & 0.68 \\
\hline $46 \mathrm{aC}$ & S \& M Water & 5 & 0.025 & 3.40 & 2.02 \\
\hline $46 \mathrm{rc}$ & S. \& $\mathrm{H}_{\text {. }}$ & 4 & 0.025 & $2.49 \#$ & $0.75 \#$ \\
\hline
\end{tabular}



(117)

Table III cont.

\begin{tabular}{llllll}
\hline 1 & \multicolumn{1}{c}{2} & 3 & 4 & 5 & 6 \\
\hline $56 \mathrm{D}$ & Boltwood & 4 & 000563 & 4.10 & 1.23 \\
$58 \mathrm{D}$ & Boltwood & 4 & 0.0632 & $3.68 \#$ & $1.10 \#$ \\
$75 \mathrm{E}$ & S. \&II.Water & 8 & 0.0565 & 2.48 & 0.78 \\
$77 \mathrm{E}$ & S. \& II. & 5 & 0.112 & 4.82 & 1.45 \\
$74 \mathrm{JE}$ & MeCoy & 8 & 0.0632 & 2.54 & 0.76
\end{tabular}

Deterainations on emanation occluded by uraninite

\begin{tabular}{llllll} 
1S"(1) & S. \& M. & 4 & 0.0265 & 4.23 & 1.27 \\
25" & S. \& M. & 4 & 0.0265 & 3.85 & 1.16 \\
3S" & S. \& M. & 4 & 0.0265 & 4.44 & 1.33 \\
4S" & S. \& M. & 4 & 0.0265 & 4.59 & 1.38 \\
\hline
\end{tabular}

Diseussion of Results in Table III.

The results obtained with electroscope

numer eight are considered the most reliable.

The ionization eurrents obtained with this

electroscope for emanation boiled off in the

Strutt and the Schlund and loore apparatus

are plotted against the weight of uranium in the

(1) I am indebted to Prof. Herman Schlundt

for these deterainations Nos is" to $4 \mathrm{~s}^{\circ}$. 



\section{(118)}

sample in the curres on eurre sheet ten. Two samples boiled off in the Sehlundt and Moore apparatus for water samples were measured in this electroscope. The first saraple number (39C) mas boiled but the steam was not allowed to completely aisplace the water in the ulb. The water in the collecting bulb and side tube thus did not reach the soiling point. It will be noted that a very low current was obtained in this case. Sample nunger (75F was hoiled until the water had been completely displaced from the bulb. The current in this case is nuch higher, and lies almost on the curve for the strutt apparatus. One sample number (74E) was b. boiled off in the MeCoy apparatus, and neasured - in this electroscope. The current in this case was lower than that obtained hy the use of the SEllundt and Moore apparatus, but higher than $t$ that obtained with the Strutt apparatus. This single result must no however be regarded as characterizing the MeCoy apparatus. More experiments are necessery to establish this point. 



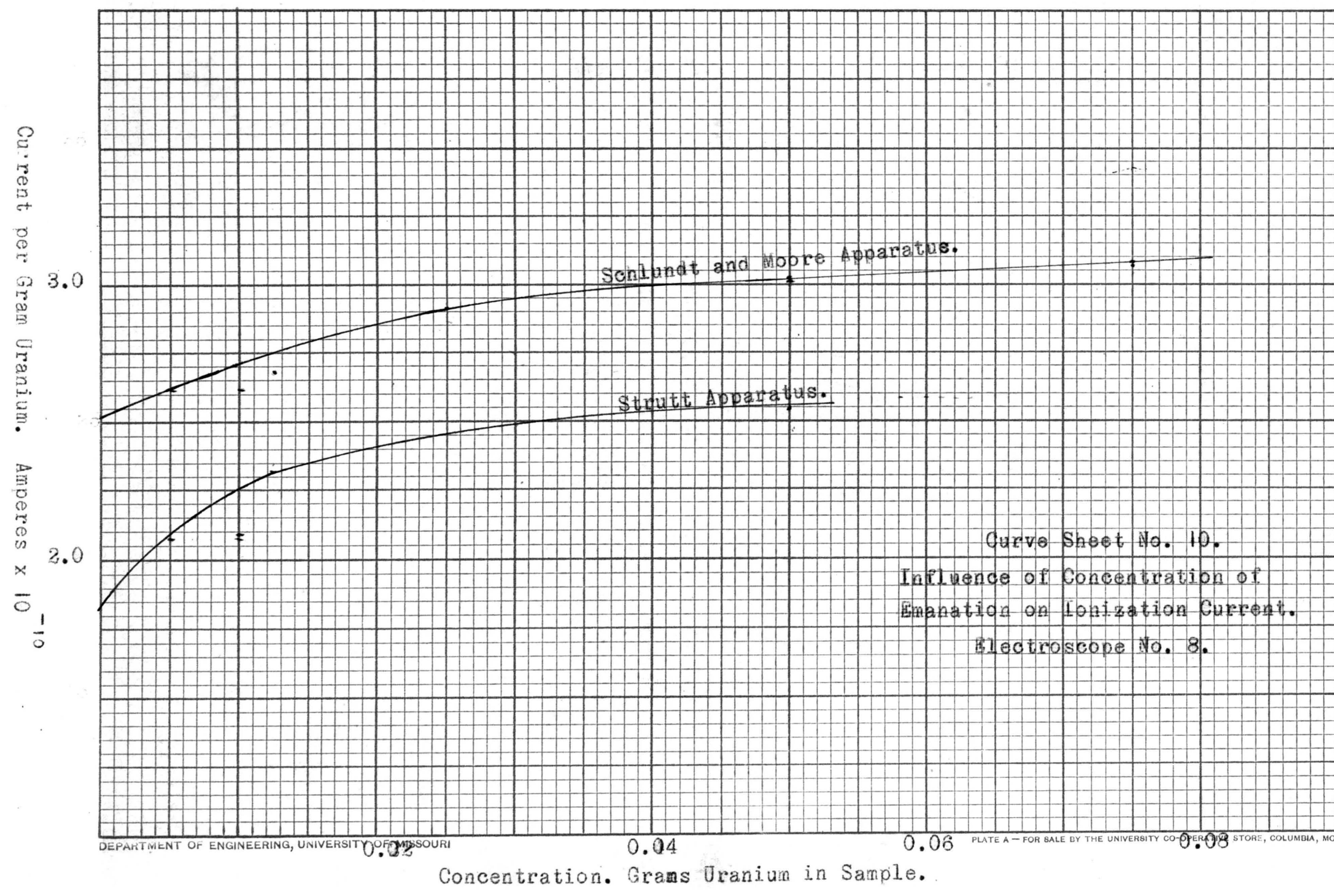





\section{(120)}

Only two reliable determinations were obtained with electroscope number two before it was converted into electroscope number eight. One of these determinations was obtained using the strutt form of apparatus for separating the eranation, and the other using the Schlundt and Moore form. The tendeney of the results wit this electroscope are in the same direction as those obtained with electroscope number two. Flectroscope number four had a mounting of the reading mieroscope which gave considerable trouble. The results obtained using the Strutt and the Sehlundt and Noore forms of apparatus for separating the emanation are very similar to thowe obtained for electroscope number eight and are shown in eurve sheet eleven. The Boltwood apparatus was used for some of the samples measu ured in this electroscope. The points obtained fall between the two curres ahove mentioned. Flectroscope nubber five had poor stop cocks, so the results obtained with this insturment are not entitled to as nuch weight as those oltained with the other electroscopes. 

(d 81$)$

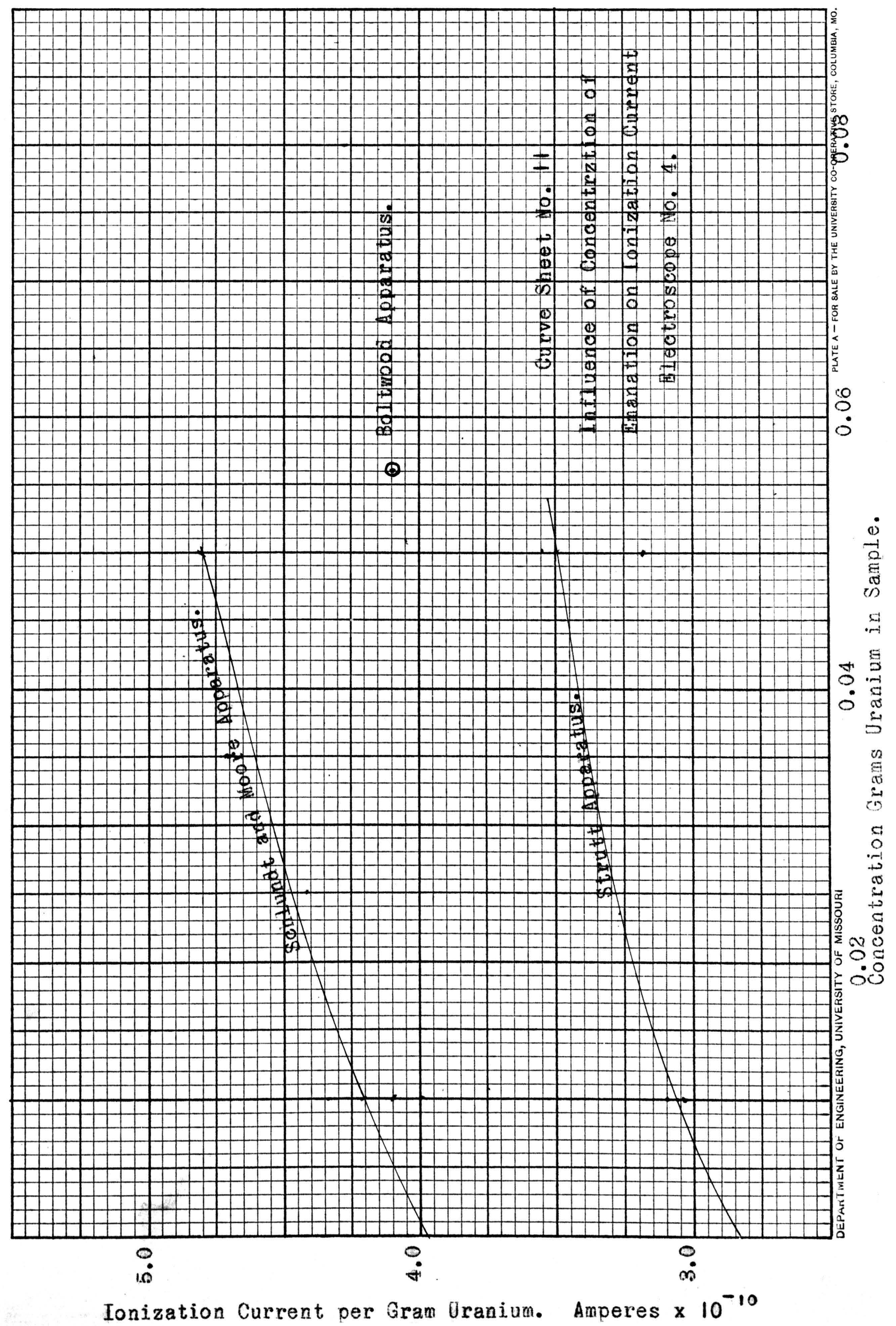





\section{(122)}

The results however show the same general tendeneyt...

The curves on the whole show that tho ionization observed in the electroscope is not proportional to the quantity of emanation in the sample. Sineerif the potential used wa not suffieient to give the saturation ionization current, there would he more recomination of $t$ the ions at higher concentrations of the radium emanation thannat low cone entrations, the ionization current at higher concentrations would then be relatively lower, which is contradictory to the observed facts in this case. The discrepaney may be explained however by assuming that there was relatively more absorption of the radiwn emanation by the wator through which the gas bubled in the separating apparatus, in the case of the samples of smaller coneentration. The faet that at the same concentration different quantities of the enanation are separated by the various forms of separating 

(123)

apparatus also seems to indicatefhat asorption of the eranation may be the cause of the discrepancy.

$$
\text { Acain in these forms of electroscopes }
$$

it is possible that the ionization is n ot directly proportional to the quantity of emanayion introduced, but no data are available upon which to nake comparisons.

$$
\text { The determinations (Is) to (4S) were }
$$
carried out by collecting the emanation oceluded in samples of the uraninite in the schlundt and Moore form of burette. (1) The value of the ionization current per gran of uranium is somewhat less than the equlinrium arount obtained y storing the solution forty days. The, saller value is probably due to the constant loss of emanation by the powdered nineral at ordinary temperatures. It will also be noted that the results are not as concordant as those obtained by storing the solution of the rineral and then separting the emantion.

Sone interesting relations betwe $n$ the ionization current and the volume of the elect- 



\section{(124)}

roscopes.appear from the data siven in table IV. The value of the average ionization eurrent per gram of uranium at the concentration of 0.05 gram of uraniun separated in the Schlundt and Moore apparatus, divided by the volune of the elactroseope is shown in colum (4) of the table.

\section{Tale IV.}

Ratio of Current to Volume.

\begin{tabular}{|c|c|c|c|}
\hline $\begin{array}{l}1 . \text { No. of } \\
\text { Elect. }\end{array}$ & $\begin{array}{l}\text { 2. I-Prgs. } \\
x 10 \text {. }\end{array}$ & $\begin{array}{l}\text { 3. Vol. of. } \\
\text { Mleet. e,e. }\end{array}$ & 4. Rati \\
\hline 2 & 2.36 & 590 & 0.00390 \\
\hline 4 & 4.80 & 952 & 0.00504 \\
\hline 5 & 4.80 & 2840 & 0.00169 \\
\hline 8 & 8692 & 565 & 0.00518 \\
\hline
\end{tabular}

It will be noted that for small electroscopes of the same design, numbers four and eight, that the ionization is nearly proportional to the volume. Electroscopes numbers two, five and eight are not of the same degign, and it will be noted that no proportionality between the ionization current observed and the volume in 



\section{(125)}

these insturments. On the basis of the results here obtained it would appear that there is no constant relation between the Boltwood radium emantion standard and the C. G. S. electrostatie standard, It also appears that the results expressed in C. G. S. electrostatic units of currentfotained ith one of the forms of electroscopes cannot be compared with the results oltained in another electroscope without reference to some other standard.

\section{Summary of Results.}

The nost important results obtained may be breifly stated ad follows:-

1. The theotetical relation between the Boltwood enanation standard and the C. G. S. electrostatic standard has been calculated.

2. It has been experinentally shown that in general no constant proportionality exists between the Boltwood emanation standard and the C. G. S. ele trostatic standard as ordinarily used. 3. But for small electroscopes of the 



\section{(126)}

same design the ionization eurrent observed is nearly proportional to the volume.

4. The various forms of apparatus used for separati/g the radiua emanation from solution have been studied and the approximate effieieney of each form deternined.

5. By calibrating the electroscope and the a paratus for separating the emention for different concentrations of radiun emant ion fairly accurate results may o obtained with the Boltwood standard. The Schlund and Moore. form of apparatus for separating the enenation gave the nost concordant results in my hands.

6. All the forms of apparatus for separating the enanation have heen succs sfully improved so as to avoid all loss of emaration in the transfer of the gas from the collecting bulb to the electroscope. 7. Two new forms of apparatus for storing solutions of radium salts have been devised.

8. A new form of electroscope has been described and its merits proven. 



\section{(127)}

9. A satisfactory method of mounting the plate glass front and back of several types of electroscopes has been workedfout.

10. A new form of mounting the reading nicroscope of electroscoped has been designed.

11. It has been shown that in the case of some electroscopes the potential is proport ional to the scale divisions, over the range of the readin microscope. Also that in other cases that this proportionallity does not hold.

12*. Small flash light batteries have been used and found satisfactory for ealibrating and chargin electroscopes.

13. A peculial "crawl" effect has been observed with electroscopes havine sulphur insulation, and the effect of this on the rate of fall of the leaf has been pointed out.

14. An amornaly in the air leak has been observed in the electrocopes used, the rate of leak decreasing with the time interval of charge of the leaf. 



\section{(128)}

From these results it is evident that the method in use for deternining the radioactivity of gases, waters, raks, and oth r comion materials by means of electroscopes should receive more careful and extended study, in a laboratory set aside for this particular purpose.

This investigation was undertaken at the suggestion of Prof. Herian Schlundt, Professor of Physical Chemistry at the University of Missouri whom I wish to thank for the many suggestions given during the course of the study. 





This thesis is nevelogo leave this room. Neither is it to beforvulodou over-
night. 
